\title{
Alalah Belgeleri Işı̆̆ında Amik Ovası ve Çevresinde Hurri Yer Adları ve Lokalizasyonları Üzerine Bir Değerlendirme
}

\author{
Oktay ÖZGÜL ${ }^{1}$ ve Beyazıt SÖYLEMEZ ${ }^{2}$
}

\section{$\ddot{O} z$}

Eski Yakındoğu dünyasının önemli halklarından biri olan Hurriler, MÖ III. binyllın sonlarına doğru Kafkaslar ve Hazar Denizi bölgesinden güneye doğru hareket ederek Doğu ve Güneydoğu Anadolu'ya, Kuzey Mezopotamya'ya, Kuzey Suriye ve Filistin bölgesine yayılmışardır. Hâkim oldukları coğrafyada yaşayan kavimleri özellikle kültürel ve dini bakımdan oldukça etkilemişlerdir. Güneydoğu Anadolu ve Kuzey Suriye'de küçük krallıklar şeklinde yaşayan Hurriler, MÖ II. binyılın ortalarına doğtu Hint-Avrupa kökenli bir halk olan Mitannilerin hâkimiyeti altına girmișlerdir. Halkının büyük çoğunluğu Hurrilerden, yönetici sınıfı ise Mitannilerden olușan Mitanni Devleti, Ön Asya'daki en önemli ve etkili siyasal yapılarından biri olmuştur. Hurriler, kültürlerini, dillerini ve dini inançlarını Mitanni ile özdeşleştirerek bu siyasal yapının içinde birçok alanda etkin rol oynamıştır. Hurrilerin siyasal anlamda varlıkları MÖ II. binyllın sonlarına doğru ortadan kalksa da Ön Asya kültürleri üzerindeki etkileri uzun süre devam etmiştir. Hurriler tarih sahnesinden çekilirken arkalarında birtakım arkeolojik kanıın yanı sıra çok sayıda yer adı da bırakmışlardır. Bu çalşşada Hurrilerin en önemli etkinlik alanlarından biri olan Kuzey Suriye bölgesinde bulunan Amik Ovası ve çevresindeki Hurri yer adlarının genel hatlarıyla bir analizi yapılmaya çalışılmıştır.

\section{Anabtar Kelimeler: Hurri, Mitanni, Amik Ovası, Levant, Yer Adları}

\section{Hurri Place Names in Amuq Plain and Surrounding in the Light of the Alalah}

\section{Documents}

\section{Abstract}

The Hurrians, one of the important peoples of the ancient Near East World, towards the end of the 3rd millennium $\mathrm{BC}$, they moved south from the Caucasus and Caspian Sea region and spread to Eastern and Southeastern Anatolia, Northern Mesopotamia, Northern Syria and Palestine. They influenced the people living in the geography they dominated, especially in cultural and religious terms. The Hurrians living in the form of small kingdoms in Southeastern Anatolia and Northern Syria, towards the middle of the second millennium BC, they came under the domination of the Mitannis, a people of Indo-European origin. The Mitanni State, whose majority of the people are Hurrians and the ruling class is Mitanni, has been one of the most important and influential political entities in Asia Minor. Hurrians have played an active role in many areas within this political structure by identifying their culture, language and religious beliefs with Mitanni. Although the political existence of the Hurrians disappeared towards the end of the IInd Millennium BC, their effects on the Near East cultures continued for a long time. As the Hurrians withdrew from the stage of history, they left behind some archaeological evidence as well as many place names.

Key Words: Hurri, Mitanni, Amuq Plain, Levant, Place Names

\section{Atıf İçin / Please Cite As:}

Özgül, O. ve Söylemez, B. (2021). Alalah belgeleri ışı̆̆ında Amik Ovası ve çevresinde Hurri yer adları ve lokalizasyonları üzerine bir değerlendirme. Manas Sosyal Arastırmalar Dergisi, 10(4), 2496-2512.

Geliş Tarihi / Received Date: 20.08.2021

Kabul Tarihi / Accepted Date: 07.09.2021

\footnotetext{
${ }^{1}$ Doç. Dr. - Kırgızistan-Türkiye Manas Üniversitesi Edebiyat Fakültesi Tarih Bölümü/ Atatürk Üniversitesi Edebiyat Fakültesi Tarih Bölümü, oktay.ozgul@manas.edu.kg,oktay.ozgul@atauni.edu.tr, oktayozgul@hotmail.com,

D ORCID: 0000-0003-0575-0436.

2 Arş. Gör. - Hatay Mustafa Kemal Üniversitesi Fen Edebiyat Fakültesi Tarih Bölümü, beyazitsoylemez@mku.edu.tr,

(iD) ORCID: 0000-0001-6545-6349
} 


\section{Giriş}

Akdeniz Bölgesi'nin Adana Bölümü'nde yer alan Hatay, batıda Toros silsilesinin bir kolu olan ve kuzeydoğu-güneybatı doğrultusunda uzanan Amanos (Nur) Dağları ile Akdeniz, güneyde Kel Dağ (Cebel-i Akra/Cassius), doğuda ise Suriye sınırları içinde kalan Kurt Dağı silsilesi ve Afrin Çayı vadisinin belirlediği bir coğrafyaya sahiptir. Hatay ilinin merkez ilçesi olan Antakya, Ölü Deniz Fay Zonu'nun kuzey ucundaki verimli Amik Ovası içinde yer almaktadır. Amik Ovası, Asi (Arantu/Orontes), Afrin (Apre/Oenoparas) ve Karasu (Labatos) vadi tabanlarının dolması sonucunda oluşmuş tektonik kökenli bir ovadır (Yener, Edens, Harrison, Verstraete ve Wilkinson, 2000, s. 168). Amik Vadisi, Anadolu yüksek yaylasını Kuzey Suriye’ye, doğudaki Mezopotamya'ya, güneydeki Filistin'e ve Mısır'a ve batıda Akdeniz Bölgesi'ne bağlayan karayollarının kavşak noktasında yer almaktadır (Yener vd., 2000, s. 165; Pamir, 2005, s. 67). Özellikle bölgenin akarsu vadileri, Amik Ovası'nı Kuzey Suriye ve Akdeniz'e bağlayan birer doğal geçit vazifesi görmektedir. Bununla birlikte bölgenin tarih boyunca en önemli coğrafi unsurlarından biri de Toros silsilesinin bir kolu olan Nur (Hamanu/Amanos) Dağları'dır. Amanos Dağları'nın, zengin hammadde kaynaklarının yanı sıra Orta Anadolu ile Kuzey Suriye arasındaki ticari ve kültürel bağ sağlayan geçitlere de sahip olması bölgenin stratejik ve jeopolitik önemini arttırmıştır. Çalışma bölgemiz, göç yollarının kavşak noktasında olmasının yanı sıra uygun iklim şartları, sulu tarıma elverişli alüvyal toprakları, zengin doğal kaynakları ve Doğu Akdeniz ticaretinde önemli bir yere sahip limanı ile en eski çağlardan günümüze kadar hem ticari hem de kültürel açıdan önemli bir cazibe merkezi olmuştur (Alkım, 1960; Alkım, 1964; Üngör, 2017, s. 218 vd.).

İkinci Dünya Savaş1 öncesinde (1931/1932) Chicago Üniversitesi Doğu Enstitüsü yöneticisi J. H. Breasted başkanlığında, R. Haines, R. J. Braidwood ve C. W. McEvan'ın da yer aldığı bir ekip oluşturulmuştur. İlk tam yönetmen C. W. McEvan'ın 1933 sonbaharında gelişiyle birlikte başlayan Doğu Enstitüsü Projesi, 1938'de Hatay'in Türkiye'ye katılmasına kadar devam eder (Breasted, 1933). Amik Araştırmaları (AS) kapsamında bölgede 178 höyük tespit edilerek belgelenmiştir. Braidwood'un gerçekleştirdiği ilk sistematik yüzey araştırması sonraki yıllarda Yakın Doğu'da gerçekleştirilecek araştırmalarda temel yöntemlerin uygulandığı bir model olması bakımından oldukça önemlidir. Tespit edilen höyüklerden toplanan keramikler ve bazılarında (Çatalhöyük, Tell Cüdeyde, Tell Tayinat, Tulail alSharqi, Tell 'Imar al-Jadid al-Sharqi, Tell Dhahab, ve Tell Kurdu) yapılan arkeolojik kazilar bölgenin Neolitik Çağ'dan (Amik A) İslamiyet'e (Amik V) kadar kültür tabakalarının alfabetik olarak kodlanmasını sağlamıştır (Braidwood, 1937; Braidwood, 1960). Bu sayede bugün hala geçerliliğini koruyan "Amik Kronolojisi" oluşturulmuştur. Amik Ovası'nın en önemli yerleşimlerinden biri olan Tell Cüdeyde'de ortaya çıkarılan tabakalanma uzun yıllar Doğu Anadolu, Güneydoğu Anadolu ve hatta İç Anadolu kültürlerinin tarihlenmesinde yardımcı olmuştur (Braidwood ve Braidwood, 1960, s. 529 vd.; Yener, 2005, s. 195). Aynı zamanda S. L. Woolley, British Museum ve Oxford Üniversitesi adına ilk olarak 1936-1939 ylları arasında yaptığı ve İkinci Dünya Savaşı nedeniyle ara verdiği Alalah (Tell Açana) kazılarına 1946-1948 yılları arasında devam etmiştir. 1995 yllında önce Chicago Üniversitesi, daha sonra da Koç Üniversitesi adına A. Yener tarafından devam ettirilen "Amik Ovası Bölgesel Yüzey Araştırmaları" ile tespit edilen ve değerlendirilen yerleşim yeri sayıs1 400’e kadar çıkarılmıştır (Yener 2005).

Neolitik Çağ’an (Amik A/B) itibaren çeşitli kültürlere ev sahipliği yapan Amik Ovası, Kuzey Irak, Kuzey Suriye ve Çukurova'ya kadar olan alanı kapsayan Güneydoğu Anadolu Kültür Bölgesi içinde yer alır. Bu dönemle birlikte geniş kapsamlı değiş tokuş/trampa ağı ile daha uzak bölgelerarası bağlantıları gösteren somut kanıtlar ortaya çıkmaya başlamıştır. Bu ağın ilk kanıtı ise Amuq A/B'de ve Orta Anadolu ile Doğu Anadolu kaynaklarından sağlanan obsidyenlerin bulunduğu Akdeniz kıyları boyunca güneye doğru olan bölgelerde görülür. Madde analizleri, obsidyen değişim ağının, Amik Vadisi'nin bir kanal görevi görmüş olabileceğini düşündüren Güney Levant'taki Eriha'ya kadar ulaşan bir rota belirlediğini ortaya koymuştur (Bressy vd., 2005, s. 1560 vdd.).

Amik Ovası, Kalkolitik Çağ’da Anadolu, Doğu Akdeniz ve Mezopotamya kültürleri arasındaki kültürel etkileşimi sağlama görevine devam etmiştir. Ova, Kalkolitik Çağ’ın erken evresini temsil eden Halaf, orta evresinde Obeyd ve geç evresinde ise Geç Uruk kültürlerinin etki alanlarında yer alır. Halaf döneminde Güney Mezopotamya kültürel bağlantılarının dışında kıyı ticareti nedeniyle Antakya ve Çukurova kıyılarının önem kazandığ1 ve bu bölgeler üzerinden, Kıbrıs da dâhil olmak üzere, tüm Doğu Akdeniz ile canlı bir iletişim yaşanmışır. Ayrıca Kalkolitik Çağ kültürel bölgesi, sadece güneye yayılmakla kalmamış aynı zamanda Doğu Anadolu ovalarına, Transkafkasya’da bugünkü Gürcistan ve Ermenistan 
içlerine kadar uzanmıştır (Özdoğan, 2011, 102 vdd.). Ancak Malatya, Elazı̆̆, Palu, Bingöl, Tatvan ve Van ovaları gibi Güneydoğu Torosların hemen kuzeyindeki ilk ova dizilerinin kuzeyinde bu kültürün giderek daha kırsal bir nitelik aldığ görülmektedir. Obeyd döneminde de her türlü maden ve doğal kaynak bakımından oldukça zengin olan Güneydoğu Toroslar, Mezopotamya kültürlerinin ilgisini çekmiştir. Bu dönemde Güney Mezopotamya-Suriye kültürlerinin Anadolu'nun bu zengin kaynaklarına yöneldikleri anlaşılmaktadır. Amik Ovası'nın Kalkolitik Çağ yerleşimlerinin en büyüğü olan Tell Kurdu'dan elde edilen sonuçlar, bölgenin Ubeyd ve Halaf dönemlerinde Orta Anadolu Platosundaki Göllüdağ kaynağından ve Bingöl yöresindeki çeşitli kaynaklardan obsidyen sağladığını göstermektedir. Arkeolojik malzemeler Tell Kurdu'nun bölgesel bir merkez olarak bölgelerarası etkileşimlerde çok önemli bir rol oynadığını ortaya koymaktadır (Bressy vd., 2005, s. 1560-1565; Yener, 2005, s. 195).

MÖ IV. binyılın sonlarında yazının keşfiyle birlikte, bazı hammaddelere gereksinimle paralel olarak artan ticaret bölgelerin birbirleriyle ilişkilerini daha da güçlendirmiştir. Bu gelişmeler de sosyo-politik ve ekonomik yapıda hızlı bir değişimi beraberinde getirmiştir. İlk Tunç Çağı'nda Anadolu, Yakın Doğu'nun geri kalan bölgelerinde olduğu gibi irili ufaklı birçok yerel beylik arasında paylaşılmıştı. Söz konusu dönemin erken evrelerinde ortaya çıan küçük şehir devletleri ilerleyen süreçte yerini daha büyük devletlere ve en sonunda imparatorluklara bırakmıştır. Yerleşim birimlerinin örgütlenmesiyle birlikte kasabaları yöneten idari sınıf ortaya çıkmıştır. Ayrıca İlk Tunç Çağı’nda bir önceki dönemin tarım, dericilik, dokumacılık, çömlekçilik gibi buluşlarına daha etkili silahların ve daha ince süs eşyalarının yapılmasını sağlayan ve bu döneme adını veren tunç madeni eklenmiştir.

Doğu Akdeniz bölümünün güneye uzantısı olan Amik Ovası, İlk Tunç Çağı’nda (MÖ ykl. 3000-2000) büyük bir göç hareketiyle karşı karşıya kalmıştır. MÖ IV. binyılın ortalarından MÖ II. binyılın ortalarına kadar kuzeyde Transkafkasya'dan güneyde Kuzey Suriye ve Filistin-Levant düzlüklerine, doğuda VanUrmiye Havzası ve Azerbaycan'a, batıda ise İç Anadolu Bölgesi düzlüklerine kadar oldukça geniş bir coğrafyaya yayılan kültür, bu geniş coğrafyada bir kültürel birliktelik sağlamıştır. Terminolojisi konusunda farklı görüşler ileri sürülen kültüre, "Kura-Aras Kültürü" (Kuftin, 1943, s. 92-123), "Khirbet Kerak Kültürü” (Amiran, 1952, s. 89 vd.; Amiran, 1965, s. 165 vd.) Yanık Kültürü” (Dyson 1973, s. 697), “Transkafkasya ve Doğu Anadolu'nun Erken Tunç Çağ1 Kültürü” (Burney, 1958), "Erken Transkafkasya Kültürü" (Burney ve Lang 1971, s. 44), "Verimli Hilal Dışındaki Kültür" (Kelly-Buccellati, 1979, s. 413-30) ve "Kırmızı-Siyah Açkılı Keramik Kültürü (Red and Black Burnished Ware)" (Braidwood-Braidwood, 1960, s. 358 vd.) gibi isimler verilmiştir. 1940’lı yıllarda Erzurum'da Karaz Höyük kazısını yapan Koşay, Anadolu'da daha önce hiçbir kazıda karşılaşılmadığını ifade ettiği bu kültür için "Karaz Kültürü" tanımlamasını kullanmıştır. Özellikle Doğu Anadolu'da uzun yıllardır çalışmalar yapan Pehlivan ve Ceylan da Karaz Kültürü adını kullanmayı tercih etmiştir (Koşay, 1948, s. 167; Koşay ve Turfan 1959, s. 359; Pehlivan, 1990, s. 168 vdd.; Ceylan, 2001a, s. 74; Ceylan, 2001b, s. 29; Ceylan, 2015, s. 477).

Günümüz Gürcistan, Azerbaycan, Ermenistan, İran, Türkiye, Suriye ve Filistin sınırları içinde çok geniş bir alana yayılan bu kültür geç aşamada çalışma bölgemizi de kapsayan Doğu Akdeniz'de "Khirbet Kerak" adıyla karşımıza çıkmaktadır. Sagona, Khirbet Kerak geleneğinin aslında daha çok "Kura-Aras III Evresi" nin geleneği olabileceğini ifade etmekle birlikte II. evrenin ikinci yarısında biçimlenmeye başladığını ileri sürer (Sagona 1984, s. 102-106). Bu kültürün Doğu Akdeniz'deki en önemli merkezleri, Amik Ovası'nda Tabara el-Akrad, Tell el-Cüdeyde, Tell Dhahab, Çatal Höyük ve Tell Tayinat; Suriye'de Ras Şamra (Ugarit), Tell Sukas, Qalat er-Russ ve Hama; Filistin'de ise Beth-Yerah, Bet Shean, Tell eshShuna ve Affulah'dır. Bu merkezlerden bazılarında yapılan arkeolojik kazılarda kültürün tipik unsurları olan çanak çömlekler, mimari yapılar ile ev içi düzenlemenin ayrılmaz ögeleri olan kil sekiler, at nalı şeklinde ocaklar, firınlar ve depolama çukurları tespit edilmiştir (Hood, 1951; Braidwood ve Braidwood 1960, s. 518 vd.; Burney ve Lang 1971, s. 50 vd.; Kelly-Buccellati, 1979, s. 420 vd.; Philip ve Millard, 2000, s. 279 vdd.; Özgül, 2011 s. 54; Özgül, 2016, s. 142).

Amik G (Braidwood, 1960, s. 259) evresinin sonunda ortaya çıkan Karaz Kültürü, bunu takip eden “Amik H" (Braidwood, 1960, s. 345) evresinde ovadaki yerleşim yerlerinde yoğun bir şekilde görülmektedir. Woollley, Filistin'deki dağınık Khirbet Kerak yerleşimlerine karşlık Amik Ovası'nda yüzeysel yapılan araştırmalara rağmen yaklaşık elli höyükte Khirbet Kerak çanak çömleğinin tespit edilmesinden yola çıkarak Amik Ovası'nın Khirbet Kerak halkının merkezi olabileceğini ifade etmektedir (Woolley, 1955, s. 8). Amik I (Braidwood, 1960, s. 396) evresinde de bölgede etkinliği devam eden bu kültür, "Amik J" (Braidwood, 1960, s. 429) evresi ile birlikte artık ortadan kaybolmuştur (Braidwood, 1960, s. 345 vd.; Tadmor, 1964, s. 260 vdd.; Sagona, 1984, s. 82). 
İlk ortaya çıkışından yaklaşık MÖ 2000’lerde sona erdiği zamana kadar Karaz Kültürü halkının kimliği hakkında bilgi veren herhangi bir yazılı kaynak bulunamamıştır. İlk Tunç Çağı boyunca geniş bir alana yayılmış olan bu kültürün farklı etnik grupların maddi kültürünü yansıttığını öne süren bazı görüsslere karşıllk kültürün belirgin türdeşliğinden de hareketle bir etnik grupla da özdeşleştirilmiştir. Burney, Karaz Kültürü’nün temsilcisi olan halkların dağlık kuzeyde bir "ana yurtlarının" olduğunu ileri sürer ve MÖ IV. binyllın sonundan itibaren bu bölgede varlığını gördüğ̈̈müz Karaz topluluklarını oluşturan "Erken Hurri" toplulukları olduğuna inanır ${ }^{3}$. Burney'in daha sonraki yayınlarında da savunmaya devam ettiği bu öneri birçok yerli ve yabancı bilim adamı tarafindan da kabul görmüştür (Burney, 1958, s. 166 vd.; Koşay ve Turfan, 1959, s. 359; Burney ve Lang, 1971, s. 47-49; Burney, 1977, s. 132; Burney, 1990, s. 45 vdd.; Ünal, 1997, s. 13; Pehlivan, 1990, s. 174 vd.; Erzen, 1992, s. 16; Kelly-Buccellati, 2004, s. 77; Ceylan, 2015, s. 477; Özgül, 2011, s. 57). Woolley ise Amik Ovası'nda yoğun yerleşimi olan Khirbet Kerak halkını ProtoHititler olarak tanımlamıştır (Woolley, 1955, s. 8).

Eski Ön Asya'nın önemli halklarından biri olan Hurriler, MÖ III. binyllın ikinci yarısından itibaren tarih sahnesinde görülmeye başlamıştır. Transkafkasya ve Doğu Anadolu üzerinden güneye doğru hareket ederek Güneydoğu Anadolu, Mezopotamya ve Akdeniz’e kadar çok geniş bir alana yayılmışlardır. Genel anlamda Hurri ülkesi, kuzeyde Kafkaslar, güneyde Suriye ve Kuzey Mezopotamya, batıda Toroslar, doğuda Zagros Dağlarına kadar olan coğrafya olarak belirlenmiştir (Burney ve Lang, 1971, s. 48 vd.; Alpman, 1981, s. 283 vd.; Roaf, 1990, s. 134; Yiğit, 2005, s. 55 vdd; Özgül, 2016, s. 142). Hurrilerin yayıllım gösterdiği bu geniş coğrafyada onların tarihlerine, kültürlerine ve dillerine ait çok sayıda arkeolojik malzeme bulunmuştur. Ancak onlarla ilgili bilgilerimiz daha çok ilişkide bulundukları Akad, Hitit, Mısır, Asur gibi kavimlerin yazılı belgelerine dayanmaktadır. Hurri hâkimiyeti ile ilgili ilk kayıtlar Akad İmparatorluğu dönemine (MÖ XXIV-XXII. yüzyllar) tarihlenir. Hurrilerin daha MÖ III. binyılda Kuzey Mezopotamya ve Doğu Dicle bölgesindeki varlıklarını Naram-Sin'in (MÖ 2254-2218) seferlerinden bahseden belgelerde geçen kişi ve yer adları sayesinde öğreniyoruz. Naram-Sin'in Kuzey Mezopotamya ve Doğu Dicle, muhtemelen Suriye'deki fetihleriyle ilgili olan ve ne yazık ki son derece kırik olarak ele geçen bir yazııında, Hurri bileşenleri ile oluşturulmuş bazı yer adları bulunmaktadır. Aynı krala ait bir yıl isminde, Aşağı Zab'daki Azuhinum Subar kenti ve adının Hurrice olduğu düşünülen kralı Tahiš-atili ismi, "NaramSin'in Azuhinum'da Subar ülkesinde zafer kazandiğr ve Tabiš-atili'yi esir aldğ̆ ynl" ifadesinde görülür. Burada geçen Azuhinum yer adı Nippur'da ortaya çıkan çok daha sonraki Eski Babil kopyasından bildiğimiz başka bir Akad metninde karşımıza çıkmaktadır (Wilhelm, 1989, s. 8; Salvini, 1998, s. 99-100; Şahin, 2015, s. 289). Bunun yanı sıra Naram-sin'in Anadolu'ya düzenlediği seferleri anlattığ1 ve Anadolu’ya dair en eski kayıtlar olarak kabul edilen Šartamhari metinlerinde de Akad kralına karşı savaşan Anadolulu krallardan biri olan Pampa adı, Nuzi belgelerinde geçen Hurri şahıs adlarını (Hašipampa, Zilipampa vb.) oluşturan bir elemandır (Ertem, 1973: 53-54; Yiğit, 2005, s. 56 vd.; Bingöl, 2013, s. 116 vdd.; Günaşdı, 2013, s. 56 vdd.; Günaşdı, 2016, s. 117).

Sümerli III. Ur Hanedanllğı dönemine ait kayıtlar, Dicle ve Fırat Vadisi'nin doğu ve kuzeyindeki dağlık bölgelerin bu dönemde, Diyala'nın kuzeyindeki doğu Dicle bölgesine de girmiş olan Hurri dili konuşan halklar tarafindan iskân edildiğini göstermektedir. Bu dönemde Hurri savaş esirleri Šulgi tarafindan alınarak Aşağı Mezopotamya'ya götürülmüştür. III. Ur Hanedanı tarafindan idare edilen küçük eyaletlerde yaşayanların isimleri çoğunlukla Hurrice olmakla birlikte bazen de Sümerce'dir (Gelb 1944, s. 112; Wilhelm 1989, s. 10).

MÖ II. binyılın ilk dönemlerine ait Hurri tarihi ve kültürünün bütünsel ve tutarlı bir şekilde ortaya koyulabilmesi mümkün olmamıştır. Ancak MÖ XVI. yüzyllın sonunda Yakındoğu'nun en önemli devletlerinden biri olan Mitanni ${ }^{4}$ Devleti, Hurrilerin bir siyasi çatı altında birleşmesini sağlamıştır. Hurriler, bu sayede özellikle Kuzey Suriye ve Mezopotamya'da etkinliklerini daha fazla arttırarak Hitit ve Misır gibi dönemin en büyük güçleri ile mücadele içine girmişlerdir. Daha önce Asur Ticaret Kolonileri döneminde Anadolu'da görülen Hurriler, bir siyasi güç olarak da yoğun bir şekilde etkileşim kurduğu Hititleri özellikle kültürel ve dini yönden oldukça etkilemişlerdir. Bu yüzden Hititlerin başkenti Hattuşa (Boğazköy) ${ }^{5}$

\footnotetext{
${ }^{3}$ Karaz Kültürü’nün Hurri topluluklarına ait olamayacağı ile ilgili görüşler için bkz. Kelly-Buccellati, 1978, s. 73; Wilhelm, 1989, s. 5-6.

${ }^{4}$ Asurluların ve Babillilerin Hanigalbat, Hititlerin Mitanni ya da Hurri, Misırlıların Nabarina (N-h-ry-n) olarak adlandırdığı bu halk kendilerine Maiteni diyordu (Breasted, 1906, s. 176 vd.; Chiera ve Speiser, 1924-1925, s. 78; Gelb, 1944, s. 70 vdd.; Astour, 1972 , s. 102-109; Ertem, 1973: 39).

5 Boğazköy'de yapılan kazılarda bulunan ve büyük çoğunluğu Hititçe olan yaklaşık 25.000 çivi yazılı tablet arasında Akadca, Sümerce, Luvice, Hattice, Palaca ve Hurrice yazılmış olanları da vardır. Sayıları ve çeşitliliği itibariyle Boğazköy belgeleri, Hurri
} 
kazılarında çok sayıda Hurri unsurunu barındıran yazılı belge bulunmuştur. Özellikle Hattuşili I'in Yıllıkları'dan, Hurrilere karşı Kuzey Suriye'nin hâkimiyetine yönelik mücadelelerle birlikte bu bölgedeki Hurri varlığının boyutu da öğrenilmektedir. Bunun yanı sıra Ugarit ${ }^{6}$, Amarna $^{7}$, Alalah ${ }^{8}$, Kültepe, Sapinuwa ${ }^{10}$, Emar $^{11}$, Urkişs ${ }^{12}$, Mari ${ }^{13}$, Çagar Bazar ${ }^{14}$ ve Rimah ${ }^{15}$ gibi Yakın Doğu'nun önemli arşivlerinde bulunan yüzlerce Hurrice şahıs ve yer adı ile tanr1 adı bu bölgelerdeki Hurri nüfuzunu göstermesi bakımından oldukça önemlidir (Burney ve Lang, 1971, s. 48 vd.; Speiser, 1941, s. 1-10; Wilhelm, 1989, s. 12 vd.; Ceylan, 1994, s. 34 vd.; Yiğit, 2005, s. 55 vdd.).

Özellikle Alalah VII ve IV. tabaka arşivlerinde ortaya çıkan yüzlerce çivi yazılı belge, bölgedeki Hurri varlığını açı bir şekilde yansıtmaktadır ${ }^{16}$. Bu belgelerde geçen şahıs adlarının \% 95'i Hurrice veya Batı Semitik (Amorit) unsurları ile birleştirilmiş Hurri terimleri içermektedir. Bu isimlerin bazıları Nuzi, Amarna ve Çagar Bazar arşivlerindeki belgelerde yerel ögeler eklenmiş halde bulunmaktadır (Wiseman, 1953, s. 9; Speiser, 1954, s. 19). Bununla birlikte Alalah çivi yazılı belgelerindeki çok sayıda Hurrice yer adı, bu göçer topluluğun gittiği her coğrafyada yaşadığı yere ad verme geleneğini burada da uyguladığını göstermektedir.

Alalah onomastikasındaki Hurri adlarının dağılımından yola çıkarak, Hurrilerin VII. tabakaya kadar Alalah nüfusunun önemli bir parçası iken IV. tabaka ve sonrasındaki dönemde artık ezici çoğunluğu oluşturduğu düşünülmektedir. Bu iki kat arasında Hurrice ve Hurrileştirilmiş isimlerin ya da terimlerin artması bu görüşü pekiştirmiştir. Hurrice terimler, tarımdan hayvancılı̆̆a, yönetimden dine ve sanata kadar pek çok alanda kullanılmışır. Hurrice olmayan kelimlerde de genellikle Hurrice ekler kullanılması dikkat çekicidir. VII. tabaka belgelerinde kullanılan Akadca'da güçlü Hurrice etkiler görülmektedir. Draffkorn’a göre, Hurrice isim ve terimlerdeki bu artısın sebebi bölgeye yeni Hurri nüfusunun gelmesidir (Draffkorn, 1959, s. 247-251). Dassow ise bu görüsse karşı çıkarak bir ismin dilinin sahibinin kökenini belirlemede

filolojisinin ana kaynağı olma özelliğine sahiptir. Burada, Mitanni kralı Tusratta’nın Mısır firavunu III. Amenhotep (MÖ 1390 1353) ile eşi Tiye ile IV. Amenhotep’e (MÖ 1353-1336) dönemin diplomasi dili olan Akadca yazdığı altı mektup bulunmuştur (Güterbock, 1967).

${ }^{6}$ Suriye'nin Akdeniz kıyısındaki önemli bir Tunç Çağı liman kenti olan Ugarit, Ras Şamra’ya lokalize edilmektedir (Bryce, 2009, s. 731).

${ }^{7}$ Nil Nehri'nin doğu kıyısında, Orta ve Yukarı Mısır sınırında, Kahire ile Luksor'un ortasında yer alan önemli bir yerleşim yeridir. Amarna (Akhetaten) 18. Hanedanlık döneminde kısa bir süre (MÖ 1347-1332) Mısır'n başkenti olmuştur (Moran, 1992; Petrie,1894).

8 MÖ 2. binyılda Amik Ovası'nın önemli bölgesel gücü olan Mukiş Krallığı'nın başkenti Tell Açana ile eşitlenmektedir. Assi Nehri'nin kenarında, 22 hektarlık bir alanı kaplayan Tell Açana, Orta ve Geç Tunç Çağları boyunca başkent özelliğini sürdürmüștür (Woolley, 1953; Woolley, 1955).

9 Kaniš/Neša, MÖ 2. binyılın ilk çeyreğinde hüküm süren Kaniš Krallığı’nın merkezi olmasının yanı sıra Koloni Çağı’nda Anadolu'da kurulan ticaret merkezlerinin (karum) başkenti/idare merkezi idi. Kültepe, Ankara'nın 320 km. güneydoğusunda, Asur'un $1000 \mathrm{~km}$. batısında yer almaktadır (Özgüç, 2004).

${ }^{10}$ Çorum il merkezinin $55 \mathrm{~km}$. güneydoğusunda, Ortaköy İlçe merkezinin $3 \mathrm{~km}$. güneybatısında yer alan önemli bir Hitit şehridir (Süel, 1998, s. 38 vdd.).

${ }^{11}$ Suriye'nin kuzeydoğusunda ve Halep’in $100 \mathrm{~km}$. güneydoğusunda yer alan günümüz Meskene şehrine lokalize edilmektedir (Beckman, 1996).

12 Suriye'nin kuzeydoğusunda, Habur bölgesinde bulunan bu önemli Tunç Çağı şehri, burada bulanan birçok mühürden yola çıkılarak Tell Mozan yerleşmesi ile eşitlenmektedir. Hurri mitolojisinde Tanrı Kumarbi'nin evi olarak geçen Urkiş, Hurrilerin önemli politik ve dini merkezlerinin başında gelmektedir. Urkiş'te, aynı zamanda Hurrilere ait olduğu kabul edilen Karaz Kültürü’nün tipik unsurlarından ocaklar ve andironlar da tespit edilmiştir (Kelly-Buccellati, 2004, s. 64).

13 Bugünkü Suriye'de, Fırat Nehri’nin batı kıyısında, Abu Kemal kasabası yakınlarındaki Tell Hariri yerleşmesi olarak düşünülmektedir. 1933 yılında tesadüfen bulunan ve kazıları devam eden Mari’de ortaya çıkarılan hem devlet hem de özel (saray personelleri) arşive ait 20.000 tablet, batıda Levant'tan Mezopotamya bölgesine, doğuda ise İran'ın batısına kadar uzanan Batı Asya'nın büyük bölümünde hüküm süren irili ufaklı birçok devlet ve toplum arasındaki siyasi ilişkileri aydınlatmaktadır. Ayrıca bu belgeler Kuzey Suriye'den Kuzey Mezopotamya'ya, doğu Dicle bölgelerine ve Zagros Dağlarına kadar uzanan bir dizi Hurri şehir devletinden de bahsetmektedir (Albright, 1937, s. 26 vdd.).

${ }^{14}$ Kuzey Mezopotamya'da Habur üçgeninde, Habur'dan Yukarı Dicle'ye uzanan ticaret yolunun üzerinde bulunan Çagar Bazar'ın Ashnakkum ile eşitliği için bkz. (Mieroop, 2004, s. 68; Bryce, 2009, s. 78).

15 Kuzey Mezopotamya'da küçük bir ticaret şehridir. Çagar Bazar'ın 145 km. doğu-güneydoğusunda bulunan Karana/Qatara ile özdeşleştirilmesi konusunda bkz. Bryce, 2009, s. 369.

${ }^{16}$ Biri Orta Tunç Çağı'na (VII. tabaka), diğeri ise MÖ 15. yüzyılın ortalarında Geç Tunç Çağı’na (IV. tabaka) tarihlenen ve şiddetli bir yıkıma uğrayan bu katlardaki arşivler, bölgenin zengin tarihi, politikası ve ekonomisine yönelik önemli belgeleri içermektedir. VII. tabaka sarayının kesin tarihi tam olarak bilinmemekle birlikte muhtemelen MÖ 18. ve 16. yüzyıllar arasına tarihlenir. VII ve IV. tabaka belgelerinin yazılması arasındaki dönemde Amik Ovası, hala Mitanni Devleti'ne bağlı Halep'in kontrolü altındaydı. IV. tabaka metinlerinin yazıldığı dönemde de Alalah kralının, Mitanni’nin "Büyük Kralı'nın vassalı olduğu anlaşılmaktadır. IV. tabaka saray arşivi, muhtemelen MÖ 15. yüzylın ikinci çeyreğinde başlayan yaklaşık 50 yıllık bir dönemi kapamaktadır, ancak metinlerin büyük çoğunluğu İdrimi'nin oğlu ve halefi Niqmepa dönemine aittir. Az sayılda metin ise, MÖ 14. yüzyllın ortalarında Hitit kralı Şuppiluliuma I tarafından şehrin yıkılmasından önce, IV. tabaka sarayının yakıldığı sırada Niqmepa'nın halefi Ilim-ilimma'nın saltanatına tarihlenmektedir (Wisemann, 1953, s. 2 vdd.; Na'man, 1979; von Dassow, 2005; Casana, 2009, s. 10 vdd.) 
güvenilir bir referans olamayacağını ifade eder. O, ayrıca Alalah'ta giderek artan Hurri varlığını, sadece bir nüfus değişiminden ziyade yerli Alalah halkının Hurri dilini ve kültürünü benimseyerek bir bakıma "kültürlenmesine" bağlamaktadır (von Dassow, 1997, s. 47 vd.). Hurrilerin yoğun olarak yaşadıkları yerlerde günümüze kadar gelen çok sayıda Hurrice yer adının bulunması onların yaşadığı yere ad verme geleneğini göstermektedir (Şahin, 2015, s. 289 vdd.). Dolayısıyla Alalah'da da yoğun bir Hurri nüfusunun bulunduğu görüşü daha kabul edilebilir görülmektedir.

İlk yazılı belgeler MÖ XVIII. yüzyllın ikinci yarısına (MÖ 1750-1700) tarihlenen (Alalah VII) tabakaya ait arşivden çıkmıştır. Söz konusu arşivdeki belgelerin büyük çoğunluğunu Yarim-lim Sarayı'na ait küçük bir odadan çıkan 175 tablet oluşturur. İkinci belge grubunu ise MÖ XV. yüzyllın ilk yarısına tarihlenen IV. tabakada Niqmepa Sarayı'nın arşivinde bulunan yaklaşık 250 adet çivi yazılı tablet oluşturmaktadır. Yanan odadan onları kurtarmaya çalışan insanlar tarafindan düşürülmüş gibi duran bu tabletlerin birçoğu parçalara ayrılmış ve okunamayacak durumdadır (Woolley, 1955, s. 103). Zengin Alalah arşivi, Akadca, Babilce, Sümerce, Hurrice ve Hititçe yazılmış tarihi, sosyal, hukuki, diplomatik, dini, kültürel ve ekonomik içeriklere sahip tabletlerden oluşmaktadır. Alalah VII ve IV. tabakalarda bulunan çivi yazılı tabletler ve özellikle Yamhad Kralı İlim-İlimma'nın oğlu Mukiş Kralı İdrimi’ye ait heykelin üzerindeki 104 satırdan oluşan otobiyografik metin, bölgenin sosyopolitik durumu hakkında önemli bilgiler vermektedir (Smith, 1949). Bu Alalah vesikaları Amik bölgesinin MÖ II. binyllın ortalarındaki siyasi, ekonomik, kültürel ve sosyal yapısına dair birincil kaynak olma özelliğine sahiptir.

Alalah belgelerinin bu kadar önemli olmasının nedenlerinden biri de Verimli Hilal'in şimdiye kadar yeterince aydınlatılamamış bir bölgesinde yer almasından kaynaklanmaktadır. Bu zamana kadar Suriye ile Anadolu arasındaki sınır bölgelerinin tarihi Boğazköy ve Ugarit belgelerinden bilinmekteydi. Ne yazık ki bunlar da MÖ II. binyılın ortasına kadar gitmeyen belgeler olduğu için bölgenin daha eski dönemleri karanlıktı. Bu bakımdan Alalah belgeleri bu boşluğun doldurulmasında önemli bir rol oynamıştır.

Alalah kazılarının epigrafik sonuçları S. Smith (1940) ve D. J. Wisemann (1953) tarafindan yayımlanmıştır. Wiseman'ın çalışması 450 'den fazla tabletin tam çevirisiyle birlikte açıklayıcı bir katalogdan oluşmaktadır. Katalogla birlikte 500'den fazla şahıs ismi, meslekler ve yer adlarının da bir listesi bulunmaktadır. Bu metinlerde geçen 250'den fazla yer adından bazıları Kuzey Suriye ve Orta Fırat bölgesinin Ugarit (RasŞamra), Halab (Halep), Tunip ${ }^{17}$, Ibla (Tell Mardikh), Emar (Meskene), Arazik ${ }^{18}$ gibi daha önceden bilinen şehirleridir (Astour, 1963, s. 221). Büyük çoğunluğu ise Alalah Krallı̆̆’na bağlı küçük kasaba ve köylere ait isimlerdir. Özellikle XV. yy tabletlerindeki şahıs isimlerinin ve yer adlarının büyük çoğunluğu Hurice'dir. Çünkü Yamhad Krallığı'nın Hititler tarafindan MÖ1550'de yıkılmasından sonra Amik Vadisi, Mitanni Krallığı’nın kontrolü alıına girmiştir. Gerek Alalah IV. tabaka çivi yazılı tabletleri gerekse İdrimi’nin heykeli üzerindeki otobiyografisi bu dönemde Mezopotamya'nın yanı sıra güney Anadolu'nun da Hurri etkisinde olduğunu göstermektedir.

MÖ XV. yüzyllın ilk yarısında yaşanan olayları anlatan Alalah Kralı İdrimi, "Hurri mubariplerinin kral,, Büyük kral Barratarna" ya sadakatini bildirerek onun vassali olduğunu ve ülkesini 30 yll idare ettiğini ifade etmektedir. İdrimi'den sonra gelen Alalah kralları (Niqmepa-İlimilimma-Itur-Addu) döneminde de Mitanni'ye olan bağıllı̆̆ın devam ettiği anlaşılmaktadır. Hitit kralı Suppiluliuma I’in önderliğinde Suriye'nin kuzeyine düzenlenen başarlı sefsonucunda Mitanni İmparatorluğu'nun başkenti Waššugani ele

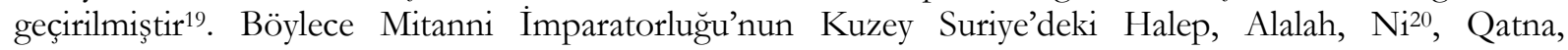
Nuhašš ${ }^{21}$ ve Kargamış gibi büyük şehirleri ile önemli bir ticaret limanı olan Ugarit Hitit hâkimiyetine geçmiştir (Smith, 1949; Kınal, 1967, s. 203 vd.; Astour, 1972, s. 103; Klengel, 1992, s. 87; Singer, 1999, s. 619; Casana, 2003, s. 85, Casana, 2009, s. 11).

\footnotetext{
${ }^{17}$ Suriye'nin Akdeniz sahillerinde ve Alalah'ın güney komşusu olan Tunip'in lokalizasyonu ile ilgili bkz: Dussaud, 1927, s. 109; Wiseman, 1953, 7; Astour, 1969, 395; RGTC IV, s. 124.

${ }_{18}$ Fırat Nehri üzerinde, Karkamış'in güneyinde yer alan Arazik, Suriye'de bulunan Aruda köyü yakınlarındaki Tell el-Hajj ile eşitlenmektedir (Astour, 1963, s. 223; Klengel, 1992, s. 62).

${ }^{19}$ Şuppiluliuma'nın Suriye seferlerinin tarihleri ve sırlaması için bkz. Kınal, 1947, s. 1-13.

${ }^{20}$ Hitit metinlerinde Ni-ia ve Ne-ya; Misır metinlerinde Ni-ya, İdrimi’nin otobiyografik yazıtında Ni-ihve Ni-hi; Alalah belgelerinde ise Ni-hi ve Ni-he olarak ifade edilen bu yer, Orta Asi Vadisi'ndeki Klasik dönem Apamea ile eşitlenmektedir (Smith, 1949, s. 48; Klengel, 1992, s. 87; RGTC 12/2, s. 211).

${ }^{21}$ Nuhašše, Halep ile Hama, orta Asi ve Suriye çölü arasına, doğuda Fırat Nehri'ne kadar olan bölgeye yerleştirilmektedir (Astour 1969, s. 386; Casana 2009, s. 18; Klengel, 1992, s. 152).
} 
Kuzey Suriye'de, dolayısıyla Amik Ovası'nda yoğunlaşan Hurri varllğının izleri, arkeolojik malzamelerin yanı sıra toponimi ve etimolojiye de yansımıştır. Alalah belgelerinin yanı sıra Hitit belgelerinde de Amik Ovası ve çevresindeki Hurri yer adlarına dair bilgi bulmak mümkündür. Çünkü kuruluşundan itibaren Hitit Krallığı'nın dış politikasında ağıllığın Güneydoğu Anadolu ve Kuzey Suriye bölgesinde olduğu görülmektedir. Hitit kralı Şuppiluliuma I, sadakatinin ödülü olarak Mukiş’e ait 42 kasaba ve küçük köyü Ugarit kralı Niqmadu II’ye vermiştir. Bu yerlerin listesi Murşili II ile Niqmepa arasında yapılan antlaşmada da, Mukiş’in karşı çıkmasına rağmen, yeniden onaylanmıştır (Klengel, 1992, s. 116; Casana, 2009, s. 25). Bu 42 yer, krallığın en kuzeyinde Mukiş sınırında yer almakta ve Asi (Orontes) Nehri'nden Akdeniz'e kadar uzanmaktadır. Bu yerlerden bazılarının Asi Nehri'nin doğusunda, hatta Halep'in güneyinde bulunduğu ileri sürülmüştür (Nougayrol, PRU 4, s. 14; Astour, 1969, s. 404). Bu topraklar kabaca kuzeyde Jebel al-Akra Dağı (Sapa/unu/Mt. Casius) ile güneyde eski Siyannu Krallığı'nın adını devam ettiren Nahr es-Sinn ve doğuda Alawite Dağlarını (JebelAnsariyah ya da Mt. Bargylus) kapsamaktadır. Niqmadu II’ye verilen toprağın yaklaşık 4.000-4.500 $\mathrm{m}^{2}$ olduğu düşünülmektedir. Bu coğrafya büyük ölçüde bugünkü Lazkiye sınırlarına karşılık gelmektedir. Böylece Ugarit Krallığı neredeyse dört kat büyüyerek isyancı Mukiş, Nuhašše ve Ni krallıklarına karşı coğrafi olarak çok daha geniş sınırlara ulaşmıştır (Astour, 1969, s. 404; Singer, 1999, s. 635).

Mısır firavunu Tutmosis III'ün Kuzey Suriye’ye düzenlediği seferlerin anlatıldığ kayıtlarda da bölgedeki Hurri yer adlarını bulmak mümkündür. Özellikle Karnak Listesi, Mısır kralının kuzeyde ele geçirdiği yerlerin listelendiği önemli bir kayıttır. Bu listedeki yer adlarılla Alalah belgelerindeki yer adları karşılaştırıldığında Tutmosis III tarafından fethedilen yerlerin büyük bir kısmının Alalah'ın hâkimiyeti altındaki yerler olduğu anlaşılmaktadır (Simons, 1937, s. 27; Albright ve Lambdin, 1957, s. 119 vdd.; Astour, 1963; Klengel, 1970, s. 179 vdd.).

Alalah'in 250'den fazla yer adı bulunan VII ve IV. tabaka metinleri, Alalah'in ve genel anlamda Halep bölgesinin toponimik durumuna 1şık tutan en önemli belgelerdir. Bir kısmının Semitik olduğu anlaşılan bu isimlerin büyük çoğunluğunun ise Semitik olmadığı ifade edilmiştir. Gelb (1961), Alalah arşivlerinde bulunan tüm yer adlarından Dimat, Huursānu, Huribte ve Maraba'nın dışındakilerin hiçbirinin Semitik olmadığını, bunların "bilinmeyen bir dilsel bağlllı̆ga" sahip olduğunu belirtmiş̧tir. $O$, sadece (a) še ekine sahip isimlerin, Nuzi gibi Hurri bölgesi dışında olmayan Hurri sosyal çevresindeki paralelliklerinden dolayı Hurrice olabileceğini belirtmektedir. Semitik olmayan isimler, sonuna eklenen eklerle tespit edilmeye çalışlııştır. Örneğin Kupper, -uwa (Azazuwa, Alaúwa, Ušuwa, S/Zuharuwa), -ija (Iburija, Kubija, Kuzubija, Uwija, Sija, Urri(ja), Zakkija, Kumlija), -ik (Apratik, Arazik, Adabik, Jarabik), -ka (Arnika, Unika, Šamuka), -(a)še (Annaše, Arinnaše, Awirraše,Hutiluraše, Šiduraše, Šuraše, Uhenaše, Tarmanaše) gibi Gelb’in son eklerine göre sinıflandırdığı Semitik olmayan bu Alalah yer adlarının Hurrice olduğunu ileri sürmüştür (Speiser, 1941, s. 116 vdd.; Kupper, 1957, s. 235; Goetze, 1958, s. 195-206).

Alalah belgelerinde geçen yer adlarından bazıları Ugarit, Nuzi, El Amarna, Çagar Bazar ve Boğazköy gibi önemli arşivlerde de yerel diyalektik değişikliklerle görülmektedir. Bu sayede bazı yerlerin bu gün nereye karşılık geldiği ile ilgili bir fikir sahibi olabiliyoruz. Ancak bu belgelerde detaylı bilgi bulunmayan bu yerlerin lokalizasyonu ile ilgili farklı görüşler ileri sürülmüştür. Bu yerlerden bazılarının lokalizasyonları ile ilgili görüşler aşağıda verilmiştir.

\section{Mukišhe}

Ugarit'in kuzeyinde, Amik Ovası'nda yer alan Mukiş, MÖ II. binyılda bu bölgeyi kontrol eden bölgesel bir krallıktır. Başkenti ise Orta ve Geç Tunç çağları boyunca aktif bir rol oynayan Alalah (Tell Açana) kenti idi (Harita-1). Mukiş, merkezi Halep'te bulunan Yamhad Krallığı'nın kontrolü altında, YarimLim Handanlığıtarafindan yönetilmekteydi. Eski Hitit Krallı̆̆’'nın Anadolu, Mezopotamya ve Misır'n birbirleriyle ilişkiye geçtiği Kuzey Suriye'yi hâkimiyeti altına alma politikası sonucunda Yamhad Hanedanlığı'nın yıkılması sonucunda bölgedeki politik denge bozulmuş ve bu boşlukta Mitanni İmparatorluğu kendini göstermeye başlamıştır. Mitanni İmparatorluğu, Hitit kralı Şuppiluliuma I'in seferlerine kadar Kuzey Suriye ve Güneydoğu Anadolu'nun büyük bir kısmını hâkimiyeti altına almıştır. Mukiş de Mitanni Kralı Barratarna döneminde batıya doğru genişleme politikasının bir sonucu olarak Mitanni idaresi altına girmiştir. Kral İlim-ilimma'nın ölümünün ardından çıkan bir isyan sonucunda oğlu İdrimi, önce Fırat Nehri üzerindeki Emar’a kaçmış ve yedi yıl sürgün hayatı yaşadıktan sonra Mitanni Kralı Barratarna ile yaptığı bağlllık yemini sayesinde Alalah tahtına oturmuştur. İdrimi’nin tahtta oturur şekilde tasvir edilen heykeli üzerinde bulunan kendi ağzından hayat hikâyesinin anlatışdığ yazıtta 30 yıllık hükümdarlığında başkenti genişlettiğini ve Hititler ile mücadele ettiğini anlatmaktadır. İdrimi’nin yazıtından 
Halep ve Emar'ın da Mitanni hâkimiyetinde olduğu anlaşlır. Ayrıca İdrimi, burada bir saray inşa ettirdiğinden bahsetmektedir ki bu saray çok sayıda yazılı belgenin bulunduğu ve muhtemelen Hitit saldırıları sonucunda yakılıp yıkılan IV. tabaka sarayıdır. Şuppiluliuma'nın Kuzey Suriye’ye düzenlediği seferler sonucunda Mitanni İmparatorluğu'nun başkenti Waşşugani ele geçirilmiş ve aralarında Mukiş'in de bulunduğu Mitanni'ye bağlı krallıklar yeminli antlaşmalarla Hitit İmparatorluğu'na bağlanmıştır. Alalah'da bir saldırı sonucunda yakılıp yıkılan IV. tabakadan sonra III. tabakadan itibaren görülmeye başlayan Hitit tapınak ve sarayları bu sürecin göstergeleridir (Kınal, 1947, s. 1-13; Woolley, 1955, s. 395; Ertem, 1973: 97; Kuhrt, 2017, s. 331).

Başkent Alalah'da bulunan zengin çivi yazılı arşivler Mukiş Krallı̆̆’’nda yoğun bir Hurri kültürünün ve nüfusunun olduğunu göstermiştir. Smith, Mukiş adının da, Akad belgelerinde bile -he çekim ekinin kullanımından da anlaşılacağı gibi, şüphesiz Hurrice olduğunu ileri sürer (Smith, 1939, s. 47).

\section{Awirraše}

Birkaç Alalah belgesinde karşımıza çıkan Awirraše'nin konumu hakkında ne VII ne de IV. tabaka belgelerinde bilgi bulunmakla birlikte bu kentin Suriye'nin batısında olabileceği belirtilmektedir. Ancak Awirraše'nin Amik Vadisi’nde olup olmadığı hala belirsizliğini korumaktadır. Özellikle tüccar Samsi-Addu ile Yamhad ya da Alalah kraliyet ailesinin bir üyesi olan Sumuna-abi arasındaki Awirrase'deki ticaret ilişkilerinin kaydedildiği belgeler (AIT 59 [22.07], (AIT 60 [22.08], AIT 63 [22.11], AIT 64 [22.12], AIT 96 [21.04], UF 36: 126-27 [22.22], UF 36: 85 [20.15], UF 36: 123[22.15].) kentin zenginliğini ve buraya verilen önemi göstermektedir. Bu belgelerden kentin Samsi-Addu ile Sumuna-abi arasında bölündüğü anlaşılmaktadır (Belmonte Marin, 2001, s. 47; Gaál, 1982, s. 13; Lauinger, 2015, s. 59 vd.).

\section{Mušuni}

Alalah arşivlerindeki nüfus listerinde (ATTT 39:1) adı geçen bu kent, doğrudan Alalah'ın kontrolü altında bulunmaktaydı. Mušuni, aynı zamanda Kadeș Savașıı'nda Hititlerin Suriye vassallarının bir listesinde $m-\check{s}-n-t(M u-s ̌ n-n-t i)$ olarak geçmektedir. Alalah Kralluğı'nın Hititler tarafindan ortadan kaldırılmasından sonra muhtemelen ayrı bir beylik olmuştur. Hama kralı Uratami'in MÖ IX. yüzylla tarihlendirilen hiyeroglif yazıtında krallığının şehirlerinden biri olarak Mu-s-ni-pz-wa-na-š(a)'dan bahseder (Laroche, 1960, s. 217).

Astour, Mušuni'yi Halep'in $28 \mathrm{~km}$. güneybatısındaki Kınnesrin ile Hama şehirlerinin ortasına yerleştirerek büyük olasilıkla da Tell Maraq’a lokalize etmektedir (Astour, 1973, s. 10). Orijinal bir Hurri toponimi olan Mušuni, çoğu zaman kişi adlarında (Ara-Mušnni/Anani-Mušuni/Penta-Mušuni/Aki-

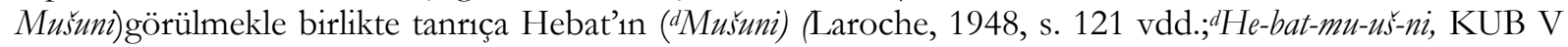
27 I 17; XXVII 1 II 37= 3 III 19; KBo XI 28 V 25, etc.- ${ }^{d} H e-b a t-m u-s ̌ u-(u n)-n i$, KUB XII 12 V 33; XXVII 22 I 19; XXXII 52,3,etc.- ${ }^{d} M u-s u-n i$, VBoT 16 Ro 13) bir sifatı ya da hipostazı olarak kullanilmaktadır (Wisemann, 1953, s. 41,44,59,66; Laroche, 1980, s. 173).

\section{Zalhe}

Birçok belgede adı geçen Zalhe'nin, büyük ve önemli bir Alalah şehri olduğu anlaşılmaktadır. Ancak Astour, bugün bölgede bu ismi çağrıștıran herhangi bir yer önermemiştir. Zalhe'nin, Amik Ovası'nın en büyük höyüklerinden biri olan ve İlk Tunç Çağ’a tarihlenen Tell Salihiyyah (AS 129) ile olan isim benzerliğinden yola çıarak buraya lokalizeedilebileceğiileri sürülmüştür. Ancak bölgedeki arkeolojik merkezlerin adlarının ve arşiv belgelerinin daha kapsamlı analizi farklı görüşlerin ortaya çıkmasını sağlayacaktır (Wisemann, 1953, s. 105; Astour,1963, s. 223; Casana, 2009, s. 22 vd.).

\section{S/Zuharuwa}

Bu yer adı Alalah VII (AIT 80 [23.04]:3-4; AIT 98a [51.06]:5 (V); AIT 86 [21.02]: 1ff.; AIT 7 [20.01]:7) ve IV. tabaka (AIT 343 [44.10]:12; AIT 161 [414.3]:49; AIT 129 [413.1] (SSAU2 Nr. 18):1; AIT 287 [431.4]:8; AIT 298 [431.13]: III 21; AIT 457 [415.19]; AIT 228 [416.3]:1; AIT 39 [417.6]:29; AIT 223 [491.1]:15; AIT 338+339 [44.7]:1) ile Ugarit (Ras Şamra) (RS 17.237+(PRU 4 63-67):22; RS 17.340+ (PRU 4 48ff.):14) arşivlerinde birkaç belgede geçmektedir. Bu isim zu- (Dietrich ve Loretz, 2004, s. 90), şú- (Zeeb, 1998, s. 841) ve sú- (Gaál, 1982, s. 11) olarak farklı şekillerde okunmuştur. Astour, Akadca suharu isminin "küçük, genç, köle"anlamlarına geldiğini ifade etmiş̧ir. Ayrıca Şuppiluliuma I tarafindan Ugarit'e bağlanan Alalah yerleşim yerleri içinde Za-za-ha-ru-wa olarak geçtiğini belirttiği bu kenti, Riha ve Qarqar arasında bulunan günümüz Sabirin ile eşitlemektedir (Astour, 1963, s. 237). Klengel, Astour'un bu lokalizasyon önerisini kabul ederek Zuharuwa'yı Ugarit ile Mukiş arasındaki sınır bölgesine yerleştirir (Klengel, 1970, s. 
76). Lauinger ise Hurrice zubri (çayır, otlak) isminden yola çıkarak bu toponimin etimoloji açısından tamamen Hurrice olabileceğini ileri sürmektedir (Lauinger, 2015, s. 288).

\section{Kunuwe}

Alalah VII. tabaka arşivindeki dört belgede (AIT 41 [20.06], 53 [22.02], 78 [23.05] ve 368 [51.05] de bilgi bulunan Kunuwe, Reyhanlı'nın güneyindeki Jebel Barisa bölgesinde bulunan Kafr Kuneiye'ye lokalize edilmiştir (Wisemann, 1953, s. 44,47,101; Astour, 1963, s. 30; Belmonte Marin, 2001, s. 168 vd.; Lauinger,2015, s. 76 vdd.). Ancak Astour'dan önce Smith, Kunuwe'nin kesin bir şekilde Kunulua/Kinalia (Tell Tayinat) olduğunu belirtmiştir. AIT 41 [20.06]'de tüccarların yöneticisi Irpa-Addu'nun AmmarAddu'ya 510 şekel borç verdiğini ve bunun karş1liğında Ammar-Addu'nun borcunu geri ödeyene kadar faiz olarak işlemesi için Kunuwe'yi Irpa-Addu'ya verdiğini öğreniyoruz. Alalah kralı Yarim-Lim (muhtemelen Yarim-Lim II), Ammar-Addu'nun Irpa-Addu'ya olan borcunu ödeyerek Ammar-Addu'yu kendine borçlu bırakmışır. Bu kez Kunuwe, teminat olarak Yarim-Lim'e verilmiştir. Yarim-lim, Ammar-Addu'nun bu borcu ödeyemeyeceğini anlamış olacak ki daha sonra Kunuwe'yi satın aldığını yine bu belgelerden ögreniyoruz (Wisemann, 1953, s. 47; Gaál, 1982, s. 19 vd.).

\section{Murmuriga/Marmaruhe}

Hitit (KBo I 1 Rs.. I 17; KBo V 6 Vs. II 8,11,18,24) (Ertem, 19736: 98), Misir ve Alalah belgelerinde adı geçen Murmuriga'nın lokalizasyonu ile ilgili farklı görüşler bulunmaktadır. Astour Alalah IV. tabaka belgelerinde bahsedilen Murmuriga (Marmaru)'y1, Amik Ovası'nda, Asi Nehri'nin kuzeyinde yer alan Mirmiran köyü ile eşitlemiştir (Harita-1) (Astour, 1963, s. 231). Ancak daha sonra bundan vazgeçerek kenti Fırat Nehri kıyısına yerleştiren Astour, buranın Hititlerin MÖ 1353’te düzenlediği Suriye harekâtında ele geçirildiğini ve Karkamış seferlerinde de önemli bir rol oynadığını ifade etmiştir (Astour, 1969, s. 405 vd.; Bryce, 2009, s. 482). Bu görüşe göre Murmuriga, Karkemišin 20 km güneyinde, Tell Ahmar yakınlarında, Sajur Nehri'nin ağzında yer almaktadır. Murmuriga, Şuppiluliuma'ya teslim olmuş ve Karkemiš'e yapılan saldırılarda bir üs haline gelmiştir. Hitit kuvvetlerinin karargâh kurmasından sonra Murmuriga, Hurriler tarafindan kuşatılmış, ancak durumu haber alan Şuppiluliuma kenti kuşatmadan kurtarmıştır. Murmuriga’yı kuşatan Hurri kuvvetlerinin Karkemiš'e kaçması üzerine Hitit kralı, Karkemiš'e saldırmış ve kenti kuşatmıştır. Ancak Murmuriga, Alalah belgelerindeki nüfus sayım listelerinde birçok tanınmış Alalah kentiarasında gösterilmektedir. Bu da biri Mukiş Krallığ1 topraklarında diğeri ise daha doğuda bulunan benzer isimli iki Geç Tunç Çağ1 şehrinin olabileceğinin kanıtı olabilir (Casana, 2009, s. 22). Bununla birlikte, Braidwood tarafindan Amik Ovasında yapılan yüzey araştırmasında Mirmiran Köyü yakınlarında tespit edilen ve Geç Tunç Çağg'na tarihlenen Tell Mirmiran (Tell Anbar) (AS 120) yerleşimi, Astour'un ilk lokalizasyon önerisinin doğru olabileceğini göstermiştir (Braidwood, 1937).

Hurrilerin, Hititler başta olmak üzere, etkileşim kurduğu halkları özellikle dini yönden etkilediğini ifade etmiştik. Hurrilerin yoğun olarak yaşadıkları Kuzey Suriye bölgesindeki bazı şahıs ve yer adlarında da onların dini unsurlarını görmek mümkündür. Çalışma bölgemizdeki bu yer adlarından biri yukarıda bahsettiğimiz tanrıça Hebat'n bir sıfatı olan Musuni'dir. Bir diğeri ise Alalah, Ugarit ve Hitit belgelerinde değişik formlarda görülen "kader, ebe, doğum tanrıçaları" olarak bilinen Hudena-Hudellura'yı işaret eden Hu-ti(l)-lu-ra-še (AT 146,9; AT 342,1; KBo XI 5 II 11;6 Vo 6; KBo XX 113 I 14; KBo XXI 87+Vo 8; KUB X 63 I 5: XXVII 1 42; KBo 27.1:10 (ChS I/5, no. 98); XXXII 128 I 20; KBo XV 37 II 7,IV 34; KBo XX 129+III 16; KUB XXXII 56 I 5; Ugar.V 526,535) (Ugar.hdn-š-thdlr-š-t)'dir (Laroche, 1980, s. 111; Speiser, 1941, s. 41, 54). Boğazköy belgelerinde (KBo 27.1:10 (ChS I/5, no. 98) bulunan Hurri doğum ritüelinde (MUNUSŠi-in-ti-ma-a-ni hu-ti-il-lu-r[i]) geçen butilluri "ebe" anlamına gelir ve Šindimani kişi adını tanımlar (Laroche, 1948, 121 vdd.; Haas, 1994, s. 372-373). Bununla birlikte Tutmosis III'ün büyük Karnak listesinde adı geçen ś-t-b-b-g (Śa-ta-bi-b-g) yer adının $S e-t a+H e-b a$ isimlerinden oluşan bir birleşik isim olduğu ve büyük Hurri tanrıçası Hebat’a adanan bir şehir olduğu sanılmaktadır. Bu Hurri kenti İdlib’in 19 km kuzeyinde, Türkiye-Suriye sınırının $12 \mathrm{~km}$ güneyinde yer alan Deir Seta yerleşimine lokalize edilir (Dussaud, 1927, map X, A-1; Braidwood, 1937, s. 36; Astour, 1963, s. 224, 231).

Alalah belgelerinde geçen Naraše (C 163,14) adı da Hurri tanrısı Nara’yı çăğıştırmaktadır. Nara, hem antlaşma metinlerinde hem de ritüel listelerinde Hurri-Hitit panteonundaki "eski tanrılar" olan Namšara, Minki, Ammunki ve Amizzadu ile birlikte zikredilir (Goetze 1958, s. 1989. 
Alalah kentlerinden biri olan "Mastabi" (C 131,7) ise Hurri savaş tanrısı Aštabi ile ilgili görülmektedir ${ }^{22}$. Aštabi, Alalah belgelerindeki şahıs adlarında da (Aštabi-Šarri, Aštabi-Šarra, Ebli-aštabi) kullanılmaktadır. Astour, Alalah hâkimiyetindeki Mastabi'yi Amik Ovası'nın Tunç Çağı merkezlerinden biri olan Tell Mastape (AS 156)'ye yerleştirir (Dussaud, 1927, har. XII 3-A; Astour, 1963, s. 237). Hurri kültür bölgesinde görülen bu tür teoforik yer adlarından Hurrilerin yaşadıkları yerleri bazı tanrı ve tanrıçalarına adadıkları anlaşılmaktadır.

Yer adları zamanla değişime uğradığından onların kayıt altına alınmaları son derece önemlidir. Bölgedeki köy ve mahalle adları çeşitli sebeplerle zamanla değiştirildiği için Tablo 1'de XVI. Yüzyıl Osmanlı Tahrir defterlerinde geçen yer adları verilmiștir (Gündüz, 2009). Bunlardan bazıları (Bitrin=Bitiren gibi) günümüzde kullandığımız Türkçe kelimelere benzer şekilde kullanılmaya devam ederken diğerleri bugün kullanılmamaktadır.

Tablo 2'deki yer adlarından bazıları Hurrice iken bazıları da (Alauwa, Atarhe, Zitarahe, Azazuwa ve Narase gibi) Hurrice son ekler almış Semitik yer adlarıdır. Alalah belgelerinde geçen Hurri yer adlarına Ebla arşivindeki çivi yazılı belgelerde rastlanmamıștır. Bunun yanı sıra Alalah belgelerinde -ḩe, $-\check{s e}$, ve $-w e^{23}$ Hurri son eklerini taşıyan yukarıda örneklerini verdiğimiz Semitik yer adlarından Ebla belgelerinde bu ekler olmadan bahsedilmiştir (Astour, 1988, s. 550).

Tablo 1. Hurrice Olması Mubtemel Günümüz Yer Adlar

\begin{tabular}{llll}
\hline Köy Adı & Kazası & Köy Adı & Kazası \\
\hline Adar(Atarhe?) & Şuğur & Huri & Antakya \\
\hline Arahiya & Altınözü & Kirekusi & Cebel-i Akra \\
\hline Armela & Şuğur & Kişkinid & Kuseyr \\
\hline Arnetya & Altınözü & Kurkun & Kuseyr \\
\hline Arani & Şuğur & Lubye (Lubwi(ja)/Lubia? & Altınözü \\
\hline Aştılas & Şuğur & Nuhiye (bkz. Nuhiwe ATT/78/2) & Kuseyr \\
\hline Atrun & Şuğur & Nişrin & Cebel-i Akra \\
\hline Bitrin (Bid/tin?) & Altınözü & Sakuriye & Kuseyr \\
\hline Berzenta (Berasena)? & Altınözü & Salkiya (Šar(ra)kuheATT/8/211) & Kuseyr \\
\hline Ekrak & Şuğur & Sudure (bkz. Šiduraše) & Kuseyr \\
\hline Hansume & Cebel-i Akra & Şirbin & Şuğur \\
\hline Harni & Cebel-i Akra & Vartan & Altınözü \\
\hline Hayno & Zilkiye & Cebel-i Akra \\
\hline
\end{tabular}

${ }^{22}$ Daha sonraki dönemlerde Batı Hurri panteonunda görülen Astabi, Ebla belgelerinde (MÖ XXIV. yüzyll) zaten kaydedilmişti. Henüz Hurrilerin Habur üçgenine yerleşmedikleri bu dönemde Astabi adının görülmesi bu tanrının aslında Sami topluluklarının panteonuna ait olduğunu göstermektedir. Daha sonra Hurri panteonuna eklenen Aštabi adına Hattuşa ve Ugarit belgelerinde de rastlanmakatadır (Laroche, 1980, s. 61; Archi, 2013, 15.).

${ }^{23}$ Hurri dilinin gramer özellikleri hakkında detaylı bilgi için bkz. Dinçol, 1970: 122-131 
Tablo 2. Alalab Belgelerinde Geçen Hurrice Olması Mubtemel Yer Adlar

\begin{tabular}{|c|c|c|c|}
\hline Abaruhe & C 161,12 & Huri (Hur-ri) & $\begin{array}{l}\text {-ATT/39/119; ATT/8/120 } \\
\text {-RS 16.146+(PRU3 182-186):10 u.;RS } \\
\text { 16.146+ (PRU3 182-186):11 } \\
\text {-KBo I } 1 \text { Vs. I 2; Rs. I 37,59,60,6,71; } 3 \\
\text { Vs. 14,31,37,38,41;Rs. 9, } \\
\text { 12,16,19,27,28,30,32,33,34,41; KBo III } 3 \\
\text { Vs. I 4; } 54 \text { 8; KBo IV 4 Rs. IV 61; } 14 \\
\text { Vs. II 10; KBo X 2 Vs. I 24; KBo XI } 20 \\
\text { 10. } \\
\text {-EA 42:10 (B H); EA 56:44 (Ertem, } \\
\text { 1973, 53-54) }\end{array}$ \\
\hline Adabik & ATT/39/82; ATT/39/59 & Hušri & $\begin{array}{l}\text { C 90,5; 141,6; 163,16; 185,18; 196,17; } \\
\text { 224,3; 223,23; 228,2; 231,6;287,5; 329,11; } \\
338,4 ; 355,6 ; 422,11 \\
\end{array}$ \\
\hline A-ak-še & C 78,6 & Hutammana & $\begin{array}{l}\text { C 152,1.2; 165; ATT/8/224; 180,21; } \\
\text { 186,3; 307,32; 343,18; ATT/47/17. }\end{array}$ \\
\hline A-al-ḩe & 181,8 & Huti(l)luraše & $\begin{array}{l}\text { AIT } 146 \text { (415.3):25; AIT 342:1 } \\
\text { Krş. hu-ti-il-lu-ur-r[i] KBo XVII } 176 \\
\text { (ChS I/5 nr. 98) }\end{array}$ \\
\hline Alawari & $\begin{array}{l}\text { ATT/8/44; ATT/8/66; C } \\
\text { 341,17;ATT/8/90 }\end{array}$ & Iarabik & ATT/8/105 \\
\hline Alaúwa & $\mathrm{ATT} / 8 / 72$ & Ituwa & $\begin{array}{c}\text { C 76, 3.; AIT 72,3 (I-tu-eki); AIT 161,1 (I- } \\
\text { tu-he) }\end{array}$ \\
\hline Alliše & ATT/39/59 & Karše & $\begin{array}{l}\text { AIT } 33 \text { (30.05):21 (R) } \\
\text { Emar } 6 \text { 274:9; 379:3; 380:15(Kar-šs; Emar } \\
6 \text { 373:90 (Kar-še); } \\
\quad \text { Emar 6 462:8 ve 524:1(Kar-) }\end{array}$ \\
\hline Anna(as)še & ATT/39/16;181,1; 311,3; ATT/8/86 & Katume & $\begin{array}{c}\text { C 145,2; 163,12; 180, 14; 181,10; 179, 2; } \\
82,13 ; 197,14.35 ; 284,7 ; 341,7 .\end{array}$ \\
\hline A(i/wi)irraše & $\begin{array}{l}\text { AIT64 AIT 64,1-2; AIT 64,3; ATT } \\
\text { 455,6; AIT 98d,6; } \\
\text { AIT 63,1-2; } \\
\text { AIT 455,21-22; AIT 96, 9f; Nuzi: a-wi- } \\
\text { iru; Ugar.:a-wa-ri-we; Boğ.: awari }\end{array}$ & Kiki & C 223,11 \\
\hline Amaršaggi & ATT $/ 8 / 192 ;$ ATT $/ 8 / 238$ & Kišadu & ATT/39/167; AIT/12/1 \\
\hline Apratik & АТT $/ 47 / 13$ & Kunuwe & $\begin{array}{l}\text { ATT/39/93; ATT/39/68; AIT/78:5; } \\
\text { AIT 41/5; AIT 53/1-2; AIT 368/2-3 }\end{array}$ \\
\hline Arazik & $\begin{array}{c}\text { ATT/39/113b; ATT/39/127; } \\
\text { ATT/39/13 }\end{array}$ & Kura & $\mathrm{ATT} / 39 / 99 ; \mathrm{ATT} / 8 / 56$ \\
\hline Ariennaše & ATT $/ 8 / 240$ & Kur-a-at & C 181,7 \\
\hline Ariante & $\begin{array}{c}\text { ATT/8/274; ATT/8/181; ATT/8/132; } \\
\text { ATT/8/286; } 341,13\end{array}$ & Kuši-ip-pu & C 107,6; ATT/8/254 \\
\hline Arnik/g/qa & ATT/8/181;ATT/87105; 220,11; 341,2 & Kuwanni & $\begin{array}{c}\text { L 109,7; C 224, r 2; AIT/343/20; } \\
\text { AIT/187/17. }\end{array}$ \\
\hline Arraphe & $\begin{array}{c}\text { AIT 416,3; AIT 82, 6-7; AIT 216, 42 } \\
\text { RGTC 2,16 (Arraphum); RGTC 4, 13; } \\
\text { RGTC 5, 38f (Arraphi); RGTC 6.1 } 29 \\
\text { (Araphi) }\end{array}$ & Lubia & ATT $/ 8 / 122$ \\
\hline Arzawa & C 298,16 & Mukišhge & 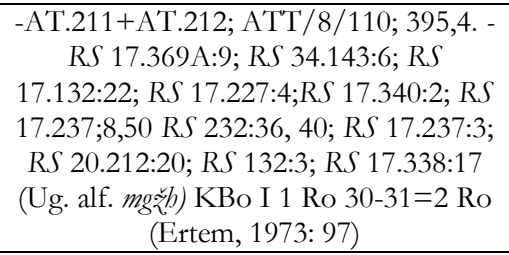 \\
\hline Aštate & C 89, 3 & & \\
\hline Atanni & C 144,1; AT/75 & Marmaruge & $\begin{array}{l}\text { AIT 185,15; AIT 163:2-4; AIT 180,1-2; } \\
\text { AIT 162: 33,34; KBo I I Rs. I 17; KBo } \\
\text { V } 6 \text { Vs. II 8,11,18,24 (Ertem, 1973: 98) }\end{array}$ \\
\hline Atalahenase & & Mušuni & $\begin{array}{l}\text {-C 139, 1; 343,5 } \\
\text {-KUB XXVII } 1 \text { IV 43; Bo 9061, 8; } 9147 \\
\text { Vo 5; KBo XXI } 34 \text { II 6; KUB XXXII } \\
\text { 19 IV 43,44; krş. Mušunnima (Ertem, } \\
\text { 1973: 98) }\end{array}$ \\
\hline
\end{tabular}




\begin{tabular}{|c|c|c|c|}
\hline Atarhe & C 161,1 & Naraše & C 163,14 \\
\hline Atrate & ATT/39/173 & Nuhiwe & ATT/78/2 (Niedorf, 1998,536) \\
\hline Awašagi & C 341,6 & Numa(a)hhe & C 181,15 \\
\hline Azazuwa & C 161,13 (Niedorf,1998, 525) & Nupanni & $\begin{array}{c}\text {-C 153,11; 457,3; } 180,38 \\
-R S \text { 17.146 (PRU } 4 \text { 154-157):38 R I); RS } \\
\text { 17.340+ (PRU } 4 \text { 48ff.):39; RS 17.237+ } \\
\text { (PRU } 4 \text { 63ff.):60; RS 17.146 (PRU } 4 \\
\text { 154-157):51 (R I). (URUNu-ba-an-ni) } \\
\text { Tiglat-pileser I: Nu-ba-na-a-še }\end{array}$ \\
\hline
\end{tabular}

\begin{tabular}{|c|c|c|c|}
\hline $\mathrm{Bi} /$ erašena & $\begin{array}{c}\text { C } 143,23 ; 300,29 ; 300,61 ; 398,3 ; 401,3 \\
\quad 402,2 ; 292,1 ; 338+339,10 ; 166,10\end{array}$ & Nummanaše & $\begin{array}{l}\text { C 187,14; 341,8; 39,8 Niedorf, } \\
\text { 1998,537); 343,36; 185,27; 78/2,4; } \\
\text { Tutmosis III listesinde Nu-ma-na. }\end{array}$ \\
\hline Bid/tin & C 266,$4 ; 266,6 ; 268,15 ; 369,8$ & Nuranti & C 176,17 \\
\hline Erirambi & ATT/39/161 & Nuraše & C 166,10 \\
\hline Gaihawa & $\mathrm{AT} / 75$ & Pahiliš & C 223,$14 ; 343,34 ; 457,38 ; 74,1$ \\
\hline Halulaše & $\begin{array}{l}\text { ATT/8/10; ATT/8/105 } \\
\text { Emar } 6 \text { 257:14 (R) uruHa-lu-la-ri; } \\
\text { Albright-Lambdin 1957, 120Ha-ru-ra-sa }\end{array}$ & Šanurhye & $\begin{array}{l}\text { C 161,17 [Śinurbena/Śinurbuna AIT } 457 \\
\text { (415.19); AIT } 163 \text { (415.9):7 }\end{array}$ \\
\hline Handukia & C 343,26 & Šar(ra)kuhe & $\begin{array}{l}\text { ATT/8/211(Albright-Lambdin, Sa-ra- } \\
k u-\check{s a} \text { ) }\end{array}$ \\
\hline Haziluhe & C 161,$14 ; 207,1 ; 303,1 ; 207: 1$ (ba-zi-lu-ube) & Šeršenina & C 305,31 \\
\hline Henzuriwe & & Sauraše & $\begin{array}{l}\text { C 185,9; Nuzi: } f \check{S} a-w i-i r-n a-a-a\left(=S_{e-w i-i r-}\right. \\
\text { na-a-a) }\end{array}$ \\
\hline Hisae & C 342,7 & Šeittimahe & C 179,3 \\
\hline Šimeri & $\begin{array}{l}\text {-C 161,R 11; 287,10; 180, 11;329, 7; } \\
\text { 343,17; 223, 5; 338+339,6 } \\
\text { (Niedorf,1998,540) } \\
\quad \text {-RS } 17.340+(\text { PRU 4, 48ff):9 }\end{array}$ & Urima & C 215, r 3 \\
\hline Šimiruši & ATT $/ 8 / 109$ & Urilu & C 306,4 \\
\hline Šija & & Uri(i)š & C 161,6 \\
\hline Šiduraše & $\begin{array}{c}\text { C 343,5; 201,16; 78/2:7; 201,13-14; } \\
\text { [187,16; 341,18. (Šituraše)] Hurr. Šidur- } \\
\text { "k1z,kı kardeş" }\end{array}$ & Urume & ATT/8/149 \\
\hline Suharuwa & $\begin{array}{c}\text { C 7,7; 80,3; 86,3; 91, r 1; 129, 1; 161, r } \\
24 ; 223,15 ; 228,1 ; 287,8 ; 298,47 ; 343,11 \\
338,1\end{array}$ & Uruhupa & C 166,12 \\
\hline Suhurri & $\begin{array}{c}\text { C 308b, 16; KUB XLVII } 1 \text { I 2,4; kbO xx } \\
\text { 126+I 14,III 41,50 }\end{array}$ & Urri(ja) & \\
\hline Šukurrie & C 161, r 7; KUB XXXII 95 Ro 9 & $\begin{array}{l}\text { Ušuwe/ } \\
\text { Ušuhe }\end{array}$ & $\begin{array}{l}\text { AIT/166 [415.11]:14,25 AIT/166 } \\
\text { [415.11]: } 26 \text { [Niedorf,1998,546 URU.Uš- } \\
w(e)] \\
\text { ATT/63 [48.20]:7 U-šu-(b)-e }\end{array}$ \\
\hline Tapduwa & C 161,6 & Ušhalatija & \\
\hline Tabawe & C 342,3 & Wa-hi & C 160,10 \\
\hline Tabbauhe & C 182,39 & Wa-ar-ri(e?) & $\begin{array}{l}\text { C 78,4; krş. } \text { wa }_{\mathbf{a}} \text {-a-ri KBo XXIII 37,4. } \\
\text { wa }_{\mathbf{a}} \text {-a-ri-ra KUB VII } 58 \text { IV 7; } \mathbf{w a}_{\mathbf{a}-\mathbf{a}} \text {-r- } \\
\text { ra KUB XLVII } 100,2 \\
\text { wa }_{\mathbf{a}-\mathbf{a}-\mathbf{a} \text {-ra, KUB XLV46,11. }}\end{array}$ \\
\hline Tapqanni & C 143,$1 ; 287,4 ; 329,9$ & Zarahe & C 181,13 \\
\hline Takuwahe & C 161,16 & Zalhe & AT.139; C 154,13; 346,5 \\
\hline Taluwa & C 408,4 & Zalatar & ATT/8/232 \\
\hline Tarmannie & C 56,2 & Zakkija & \\
\hline Tarmanaše & $\begin{array}{c}\text { C 163,13; 341,8; 342, } 13 \text { (Goetze 1958, } \\
\text { 198-199) }\end{array}$ & Zalwar & ATT/39/4 (Ša?-lawari, C 190,1) \\
\hline Tiliše & C 185,$6 ; 193,1 ; 223,31 ; 287,6$ & Zallarišena & АTТ/8/142 \\
\hline Timuhe & C 161,8 & Zazallaše & \\
\hline Uhenaše & C 428,3;159,3 & Zitarahe & ATT/8/252 \\
\hline Uhhija & & Ziúraše & $\begin{array}{l}\text { ATT/8/240 Tutmosis III listesinde Ti- } \\
\text { yu-ra-sa) }\end{array}$ \\
\hline Ura & $\begin{array}{l}\text { ATT/78/21 [41.94]:8 (Zeeb, 1998, Nr. } \\
\text { 32) C 142,13; 154,10 }\end{array}$ & Zizura & C 223,9 \\
\hline Urie & ATT/39/161; 105,1; 162,3.16 (U-ur-ri) & Zuwe & \\
\hline Uriešše & C 146,18; C $161[414.3]: 7$ & Zuzzura & $\begin{array}{l}\text { C 78,5; ATT/79/3 [414.15]:3 (Niedorf, } \\
\text { 1998: 551) }\end{array}$ \\
\hline
\end{tabular}




\section{Sonuç}

Kuzey Levant'ın başlangıcında yer alan Amik Ovası'nın MÖ III. binyılın sonlarına doğru Kafkaslar ve Doğu Anadolu'dan güneye hareket ederek Kuzey Suriye ve Filistin'e kadar yayılan Hurrilerin önemli bir yerleşim bölgesi olduğu gözlemlenmiştir. MÖ III. binyllın ortalarına tarihlenen ve Hurrilere ait olduğu kabul edilen Karaz Kültürü’nün karakteristik unsurları, gerek arkeolojik kazılarda gerekse yüzey araştırmalarında pek çok yerleşim yerinde ortaya çıkarılmıştır. Alalah belgelerinde bulunan yüzlerce Hurrice şahıs ve yer adının yanı sıra Hurri ay isimleri ile Hurrice terimler bu bölgede yoğun bir Hurri varlı̆̆ına işaret etmektedir. Bu yerlerden bazıları Alalah Kralluğı’nın hâkimiyeti altında iken bazıları ise daha uzak bölgelerde yer almaktadır. Alalah belgelerinde geçen bazı yer adlarından, genellikle bir kişinin memleketi ya da kökeni verilirken bahsedilir ve bu da ne yazık ki bu yerlerin tespit edilmesine yardımcı olmaz. Bölgedeki Hurri yer adlarının bir kısmının adı zamanla değişmiş olsa da küçük ses değişimleriyle varlığını halen devam ettiren yer adları da bulunmaktadır. Alalah belgelerinin yanı sıra Kültepe, Boğazköy ve Šapinuwa belgelerinde de geçen Hurrice isimler ve terimler, Hurrilerin Anadolu'da hem nüfus hem de kültürel olarak üstün bir konumda olduklarını göstermektedir24.

Bu bölgede Hurri nüfusunun giderek artması, beraberinde Hurri kültürü ve geleneklerinin bölge kültürleri üzerinde belirgin bir etki bırakmasına ve bunların yazılı belgelerinde Hurri şahıs ve yer adlarının daha sık görülmesi sonucunu doğurmuştur. Başta Alalah VII ve IV. tabaka arşivleri olmak üzere yukarıda verdiğimiz Yakındoğu'nun önemli arşivlerinde birçok Hurri şahıs ve yer adının geçtiği yüzlerce çivi yazılı belge olduğundan bahsetmiştik. Bu durum, Amik Ovası'nın sahip olduğu konum dolayısıyla farklı etnik unsurları bünyesinde barındırmasının doğal bir sonucudur.

Tarihsel toponimin evrensel öğretisinin özeti şudur: coğrafi isimlerin ekleri ya isimlerin köküyle aynı dile aittir ve o dilin ilk ortaya çıtı̆ğ zamana kadar eskiye gider, ya da bir şekilde yoğun bir etkileşim kurduğu yabancı bir dilden alınarak isimlere eklenmiştir. Hurri topluluklarının Kuzey Suriye’ye yoğun göçü sonucunda ortaya çıkan Hurri yer adlarıyla, bölgede onlarla birlikte bulunan Semitik halklarla kültürel etkileşimin bir sonucu olarak Hurri eklerini alan Semitik kökenli çok sayıda yer adının bulunması bu duruma güzel bir örnektir.

Alalah belgelerinde geçen Hurri yer adlarının birçoğunun bugün Amik Bölgesi’nde bulunan yüzlerce arkeolojik merkezden hangisiyle eşitlenmesi gerektiği büyük bir sorun olarak karşımızda durmaktadır. Mitanni Devleti'nin en önemli etki alanlarından birisi olan bu bölgede yapılacak geniş kapsamlı çalıssmalar bu sorunun büyük oranda çözülmesine önemli katkı sağlayacaktır.

\section{Etik Beyan}

"Alalah Belgeleri Işı̆ğnda Amik Ovası ve Cevresinde Hurri Yer Adlar ve Lokalizasyonlar Üzerine Bir Degererlendirme” başlıklı çalışmanın yazım sürecinde bilimsel kurallara, etik ve alıntı kurallarına uyulmuş; toplanan veriler üzerinde herhangi bir tahrifat yapılmamış ve bu çalışma herhangi başka bir akademik yayın ortamına değerlendirme için gönderilmemiştir. Bu araştırmada hazır veri seti kullanıldığı için etik kurul kararı zorunluluğu taşımamaktadır.

\section{Kaynakça}

Alagöz, C. A. (1984). Türkiye yer adları üzerine bazı düşünceler. Türk Yer Adlan Semposynumu Bildirileri. 11-13 Eylül 1984. Ankara, ss. 11-23.

Albright, W. F. (1937). Western Asia in the twentieth century B.C., The archives of mari. American Schools of Oriental Research, 67, 26-30.

Alkım, U. B. (1960). Sam'al ile Asitawandawa Arasindaki Yol, Amanus Bölgesinin Taribi Coğrafyasma Dair Arasstrmalar", Belleten, XXIV, Ankara, ss. 349-399.

Alkım, U. B. (1967). İslahiye bölgesi araştırmaları, Tilmen ve Gedikli (Hüyük) Kazıları 1964. TAD, XIV-I-II, Ankara, 69-78.

Amiran, R. (1952). Connections between Anatolia and Palestine in the early bronze age. Israel Exploration Journal, 2, 89-103.

Astour, M. C. (1963). Place-names from the Kingdom of Alalah in the North Syrian List of Thutmose III, A Study in Historical Topography. Journal of NearEastern Studies, 22(4), 220-241.

Astour, M. C. (1969). The partition of the confederacy of Mukiš-Nuhiašše-Nii by Šuppiluliuma, a study in political geograph of the Amarna Age. Orientalia, 38(3), 381-414.

${ }^{24}$ Gelb (1935, s. 16), Kültepe tabletlerinde geçen az sayıdaki Hurri şahıs adından yola çıkarak Hurrilerin Anadolu toplumları içinde yoğun bir grubu oluşturmadıklarını ifade eder. Belgelerde ismi geçen az sayıdaki Hurrilerin de zaman zaman kuzey Mezopotamya'dan ve belki de komşuları Asurlularla birlikte gelenler olduğunu ileri sürmektedir. 
Astour, M. C. (1988). Toponymy of Ebla and ethnohistory of Northern Syria, a preliminary survey. Journal of the American Oriental Society, 108(4), 545-555.

Astour, M. C. (1972). Hattusilis, halab and hanigalbat, JNES, 31(2), 102-109.

Astour, M. C. (1973). Note toponymique à la tablette A. 1270 de Mari. Revue d'Assyriologie et D'archéologien Orientale, 67(1), 73-75.

Beckman, G. (1996). Emar and its archives. Emar, the History, Religion and Culture of a Syrian Town (Edt: M. W. Chavalas,). pp. 1-12.

Belmonte Marin, J. A. (2001). Repertoire Geographique des Textes Cuneiformes XII/2, Die Orts-und Gewassernamen der Texte aus Syrien im 2.Jt. v. Chr., Wiesbaden.

Bilgiç, E. (1946). Anadolu'nun ilk yazılı kaynaklarındaki yer adları ve yerlerinin tayini üzerine incelemeler. Belleten, $X(39), 381-423$.

Bingöl, A. (2013). Hurriler'in siyasi organizasyonlar1. Eržincan Üniversitesi Sosyal Bilimler Enstitüsü Dergisi, 6(1), 115-133.

Braidwood, R. J. (1937). Mounds in the plain of antioch, an archaeological survey. Oriental Institute Publications, Chicago.

Braidwood, R. J. ve Braidwood, L. S. (1960). Excavations in the Plain of Antioch I. The Earlier Assemblages Phases A-J, The Oriental Institute of the University of Chicago, Oriental Institute Publications 61, Chicago.

Bressy, C., Poupeau, G. ve Yener, K.A. (2005). Cultural interactions during the ubaid and halaf periods: Tell kurdu (Amuq Valley, Turkey) Obsidian Sourcing. Journal of Archaeological Science 32, 1560-1565.

Bryce, T. R. (2009). The Routledge Handbook of The Peoples and Places of Ancient Western Asia, The Near East from the Early Bronze Age to the fall of the Persian Empire, Abingdon.

Burney, C. A. (1958). Eastern Anatolia in the chalcolithic and early bronze. Anatolian Studies, VII-I, 157-209.

Burney, C. A. ve Lang, D. M. (1971). The peoples of the hills, ancient ararat and Caucasus. London.

Burney, C. A. (1977). From village to empire, an introduction to near eastern archaeology. Oxford.

Burney, C. A. (1990). The indo-european impact on the hurrian World. When Worlds Collide, The Indo-Europeans and Pre-Indo-Europeans, (Edit T.C. Markey and J. A. C. Greppin), Ann Arbor, 45-52.

Casana, J. (2009). Alalakh and the archaeological landscape of mukish, the political geography and population of a late bronze age kingdom. Bulletin of the American Schools of Oriental Research, 353, 7-37.

Casana, J. (2003). From Alalakh to Antioch, Settlement, Land Use, and Environmental Change in the Amuq Valley of Southern Turkey, Volum One, Chicago.

Ceylan, A. (1994). Eski anadolu devletler arası ilişkiler, antlaşmalar (II. ve I. Binde) (Doktora Tezi). Atatürk Üniversitesi Sosyal Bilimler Enstitüsü, Erzurum.

Ceylan, A. (2001a). 1999 yılı Erzincan ve Erzurum yüzey araştırmaları. 18. Araștırma Sonuclar Toplantısı, 2, 71-82.

Ceylan, A. (2001b). Erzurum ovası'nda önemli bir merkez, cinis höyük. Atatürk Üniversitesi Fen-Edebiyat Fakültesi Edebiyat Bilimleri Araştırma Dergisi, 26, 29-41.

Ceylan, A. (2015). Doğu anadolu araştırmalar II (Eræzurum-Erzincan-Kars-Iğdır) (2008-2014). Erzurum: Atatürk Üniversitesi Yayınlar1.

Chiera, E. ve Speiser, E. A. (1924-1925). A new factor in the history of the ancient east. AASOR, 6, 75-92.

Dietrich, M. ve Loretz, O. (2004). Alalah-Texte der Schicht VII (I). Historische und juristische Dokumente”, UF 36, 43-150.

Dinçol, A. M. (1970). Eski anadolu dillerine giriș. İstanbul: Edebiyat Fakültesi Basımevi.

Dussaud, R. (1927). Topographie Historique De La Syrie Antique Et Médiévale, Librarie Orientaliste Paul Geuthner, Paris.

Draffkorn, A. E. (1959). Hurrians and hurrian at alalakh, an ethno-linguistic analysis. A Dissertation in Oriental Studies.

Erzen, A. (1992). Doğu anadolu ve urartular. Ankara: Türk Tarih Kurumu Yayınlar1.

Gaál, E. (1982). On the Chronology of Alalah Level VII. Annales Universitatis Scientiarum Budapestinensis de Rolando Eötvös nominatae, Sectio Historica (AUSB) 22, 3-53.

Gelb, I. J. (1935). Inscriptions from alishar and vicinity. Illinois: The University of Chicago Oriental Institute Publications.

Gelb, I. J. (1944). Hurrians and subarians. Chicago: The University of Chicago Press.

Gelb, I. J. (1961). The early history of the west semitic peoples. Journal of Cuneiform Studies, 15(1), 27-47.

Gelb, I. J. (1962). Ethnic reconstruction and onomastic evidence. Names, 101, 45-52.

Goetze, A. (1959). Hurrian place names in $-\check{s}(\breve{s})$ e. Festschrift Johannes Friedrich, Heidelberg, 195-206.

Günaşd1, Y. (2013). Karasu (yukar) havæasindaki taribi ve arkeolojik veriler (Doktora Tezi). Atatürk Üniversitesi Sosyal Bilimler Enstitüsü.

Günaşdı, Y. (2016). Geçitler ülkesinde geçitler ülkesinde önemli bir urartu kalesi: Avnik. TÜBA-AR, 19, 113-135.

Gündüz, A. (2009). XVI. yüzyllda antakya kazası (1550-1584), Antakya.

Güterbock, H. G. (1967). Siegel aus Boğąkö̈y, erster teil die königssiegel der grabungen bis 1938, Osnabrück.

Hood, S. (1951). Excavations at tabara el-akrad. Anatolian Studies, I, 113-147.

Kelly-Buccellati, M. (1979). The fertile crescent culture, north eastern connections of syria and palestine in the third millennium B.C., Ugarit-Forschungen, 11, 413-430.

Kelly-Buccellati, M. (2004). Andirons at urkesh, new evidence for the hurrian identity of the early trans-caucasian culture. Ancient Near Eastern Studies 12, A View From the Highlands, Archaeological Studies in Honor of Charles Burney, (Edt. Antino Sagona), 67-89.

Klengel, H. (1970). Geschichte Syriens im 2. Jahrtausend v.u.Z., Band 3. Historische Geographie und allgemeine Darstellung, Berlin. 
Klengel, H. (1992). Syria 3000 to 300 B.C., A Handbook of Political History, Berlin.

Koşay, H. Z. (1948). Karaz sondaj1. Türk Tarih Kongresi, 3, 165-169

Koşay, H. Z. ve Turfan, K. (1959). Erzurum-karaz kazısı raporu. Belleten, 23 (91), Ankara, 349-413.

Kuftin, B. A. (1943). An urartian columbarium on the slopes of ararat and the copper age of kura-arax basin. Vestnik Gosukarstvennogo Mureja (XIIIB), 92-123.

Kupper J. R. (1957). Les nomades de mésopotamie au temps des rois de Mari, Les Belles-Letters, Paris.

Kupper J. R. (1973). Northern mesopotamia and syria. Cambridge University Press, 1-41.

Lauinger, J. (2015). Following the man of yambad, settlement and territory at old babylonian alalah. Brill Academic Publishers.

Moran, W. L. (1992). The amarna letters. London: The Johns Hopkins University Press.

Na'man, N. (1979). The chronology of alalakh level VII once again. $A S, 29,103-113$.

Nashef, K. (1991). Répertoire géographique des textes cunéiformes IV, Die Orts- und Gevässernamen der altassyrischen Zeit, Wiesbaden.

Nougayrol, J. (1959). Le Palais Royal D’Ugarit IV. Textes accadiens des archives sud. Mission de Ras Shamra IXI Paris.

Pamir, H. (2005). The orontes delta survey. The Amuq Valley Regional Projects Volume 1, Surveys in the Plain of Antioch and Orontes Delta, Turkey, 1995-2002, (Edt: K. A. Yener. Oriental Institute Publications, No: 131, 67-98.

Özgüç, T. (2004). Kültepe, Kanišs/Neša. İstanbul: Yap1 Kredi Yayınları.

Özgül, O. (2011). Eskiçağ'da (Yukar) Aras Vadisi (Doktora Tezi). Atatürk Üniversitesi Sosyal Bilimler Enstitüsü.

Özgül, O. (2016). Erzurum'da stratejik bir urartu kalesi, Tepeköy (Pir Ali Baba), Tüba-ar 19, 137-157.

Pehlivan, M. (1990). Karaz ve hurriler. 100. Yal Üniversitesi Sosyal Bilgiler Dergisi, 1, 168-176.

Sagona, A. (1984). The Caucasion Region in the Early Bronze Age, Part 1-3, BAR International Series 214 (iii), Oxford.

Sagona, A. (2014). The Kura-Araxes Culture Complex, A History of Early Research, Arkeolojizle Geçen Bir Yaşam İcin Yazılar, Veli Sevin'e Armağan, (Edit Aynur Özfirat), Ege Yayınları, İstanbul.

Salvini, M. (1998). The Earliest Evidence of Hurrians Before the Formation of the Region of Mitanni, Urkesh/Mozan Studies 3, Urkesh and the Hurrians Studies in Honor of Lloyd Cotsen Bibliotecha Mesopotamia 26, 99115.

Speiser, E. A. (1941). Introduction to Hurrian, American Schools of Oriental Research New Haven Under The Jane Dows Nies Publication Fund, Baltimore.

Singer, I. (1999). A political history of ugarit. Handbook of Oriental Studies, Section 1, The Near and Middle East, 39, 603733.

Smith, S. (1940). Alalakh and chronology. London: Cambridge University Press.

Smith, S. (1949). The statue of 1 drimi. London: BIAA.

Şahin, H. A. (2015). Kültepe metinlerindeki huri kültür unsurlarının doğu anadolu'daki kanıtları ve hurrilerin göç yolları. Uluslararası Doğu Anadolu Güney Kafkasya Kültürleri Sempozyumu Bildirler II, (Edt: M. Iş1kl1-B. Can). Newcastle: Cambridge Scholars Publishing. pp. 289-298.

Tadmor, M. (1964). Contacts between the 'amuq and syria-palestine (Review-article). Israel Exploration Journal, 14(4), 253-269.

Ünal, A. (1997). Hurriler, hurri tarihi, kültürü ve arkeolojisiyle ilgili yeni buluntular ve gelişmeler. 1996 Yıl Anadolu Medeniyetleri Müzesi Konferanslar, Ankara 1997, 11-29.

Üngör, İ. (2017). Gaziantep ili nurdağ1 ilçesi’nde tarihi ve arkeolojik çalışmalar. Akademike Tarih ve Düs̆̈̈nce Dergisi, IV (XIII), 213-263.

Wilhelm, G. (1989). The Hurrians. Warminster.

Wisemann, D. J. (1953). The Alalakh Tablets. British Institute at Ankara, Ankara.

Woolley, S. L. (1955). Alalakh, an account of the excavations at tell atchana in the hatay, 1937-1949. Printed at the University Press b Charles Batey for The Society of Antiquaries Burlington House, London.

van de Mieroop, M. (2004). A bistory of the ancient near east ca. 3000-323 BC, Oxford.

von Dassow, E. M. (1997). Social Stratification of Alalab Under The Mittani Empire, New York University.

von Dassow, E. M. (2005). Archives of Alalah IV in Archaeological Context, BASOR, No. 338, 1-69.

Yener, K. A. (2005). Conclusions. The Amuq Valley Ragional Projects Volume 1, Surveys in the Plain of Antioch and Orontes Delta, Turkey, 1995-2002”, (Edt: K. A. Yener). The Oriental Institute of the University of Chicago Oriental Institute Publications, No. 131, Chicago.

Yener, A., Edens, C., Harrison, T. P., Verstraete, J. ve Wilkinson, T. J. (2000). The amuq valley regional project, 1995-1998. AJA, 104(2), 163-220.

Yiğit, T. (2005). Hurrilere ilişkin Hititçe çivi yazılı belgelerdeki ilk kayıtlar. TAD, 38, 55-69.

\section{EXTENDED ABSTRACT}

Located in the Adana part of the Mediterranean Region, Hatay is surrounded by the Amanos (Nur) Mountains and the Mediterranean in the west, Kel Mountain (Cebel-i Akra / Cassius) in the south, and the Kurt Mountain range in Syria and the Afrin Stream valley in the east. Antakya, the central district of Hatay province, is located within the fertile Amuq Plain at the northern end of the Dead Sea Fault Zone. Amuq Valley is located at the crossroads of highways connecting the Anatolian Highland to Northern Syria, Mesopotamia in the east, Palestine and Egypt in the south and the Mediterranean region in the west. 
In particular, the river valleys of the region serve as natural passages connecting the Amuq Plain to Northern Syria and the Mediterranean.

In the Amuq Plain between the summer of 1932-1938, 178 mounds were identified and published in the Amuq Plain Regional Project, which were given by a team of R. J. Braidwood and C. W. Mc Evan, under the chairmanship of J. H. Breasted on behalf of the Oriental Institute of Chicago University.Ceramics collected from the identified mounds and archaeological excavations in some of them (Çatalhöyük, Tell Cüdeyde, Tell Tayinat, Tulail al-Sharqi, Tell 'Imar al Jadid al-Sharqi, Tell Dhahab, ve Tell Kurdu) enabled the cultural layers of this region to be coded alphabetically from the Neolithic Age (Amuq A) to Islamic (Amuq V). The Plain, which has hosted various cultures since the Neolithic Age (Amik A/B), has also attracted the attention of the Hurrians, who are the representatives of one of the important peoples of Ancient Near East World. Hurrians moved south through Transcaucasia and Eastern Anatolia and spread over a wide area as far as Southeast Anatolia, Mesopotamia and the Mediterranean. In this vast geography where the Hurrians spread, many materials belonging to their history, culture and language were found. At the end of the sixteenth century BC, the kings of Mittani in Upper Mesopotamia united most of the Hurrian-speaking countries under their control. In this way, it increased its effectiveness especially in Northern Syria and Mesopotamia and struggled with the greatest states and empires of the period such as Hittite and Egypt.

Alalah level VII and level IV documents clearly reflect Hurri presence in the region. The great majority (perhaps as much as ninety-five per cent.) of the names are Hurrian or contain Hurrian elements combined with possible West-Semitic (Amorite) elements. In addition, the numerous Hurrice place names in the Alalah documents show that this nomadic community followed the tradition of naming the place where they lived in the geography.

Based on the distribution of the Hurri names in the Alalah onomastic, it is thought that the Hurrians were an important part of the Alalah population up to Level VII, now constituting the overwhelming majority in the period IV and beyond. The increase of Hurrians and Hurrized names or terms between these two levels reinforces this view. Hurrian terms have been used in many fields, from agriculture to animal husbandry, from management to religion and art.

The traces of the Hurrian presence concentrated in the north of Syria are reflected in the topony and etymology as well as the archaeological materials. In addition to the Alalah documents, it is possible to find information about the Hurri place names in the Amuq Plain and its surroundings in the Hittite documents. Because since its establishment, it is seen that the dominance of the Hittite Kingdom's foreign policy is in the Southeastern Anatolia and Northern Syria regions. The Hittite king Suppiluliuma I gave 42 towns and small villages belonging to Mukiş to the Ugarit king Niqmadu II as a reward for his loyalty. It is possible to find many place names in the region in the records where the Egyptian pharaoh Tutmosis III's voyages to Northern Syria are described.

Alalah's level VII and level IV texts with more than 250 place names are the most important documents that shed light on the toponymic situation of Alalah and the Aleppo region in general. Gelb (1961) stated that all the place names in the Alalah archives except Dimat, Hursānu, Huribte and Maraba were not Semitic, and they had an "unknown linguistic affiliation". He states that only names with the suffix (a) še can be Hurrians due to parallels in the Hurrian social environment. Non-Semitic names are tried to be determined by adding suffixes to the end. For example, Kupper claimed that these non-Semitic Alalah place names such as -uwa, -ija, -ike, -ka, (a) see, which Gelb classified according to suffixes, were Hurrians.

Hurri place names in Alalah documents are not found in cuneiform documents in Ebla archive. In addition, in the Alalah documents, Semitic place names bearing -he, $-\check{s} e$, and -we Hurri suffixes are mentioned without these attachments in Ebla documents.

As a result, it has been observed that the Amuq Plain, located at the beginning of the Northern Levant, is an important settlement area of the Hurrians. Some of these places are under the rule of the kingdom of Alalah, while some are located in more remote areas. Some of the place names in Alalah texts are often mentioned when giving a person's hometown or origin, which unfortunately does not help identify these places. Although the names of some of the Hurri place names in the region have changed over time, there are also place names that still exist with minor sound changes. 


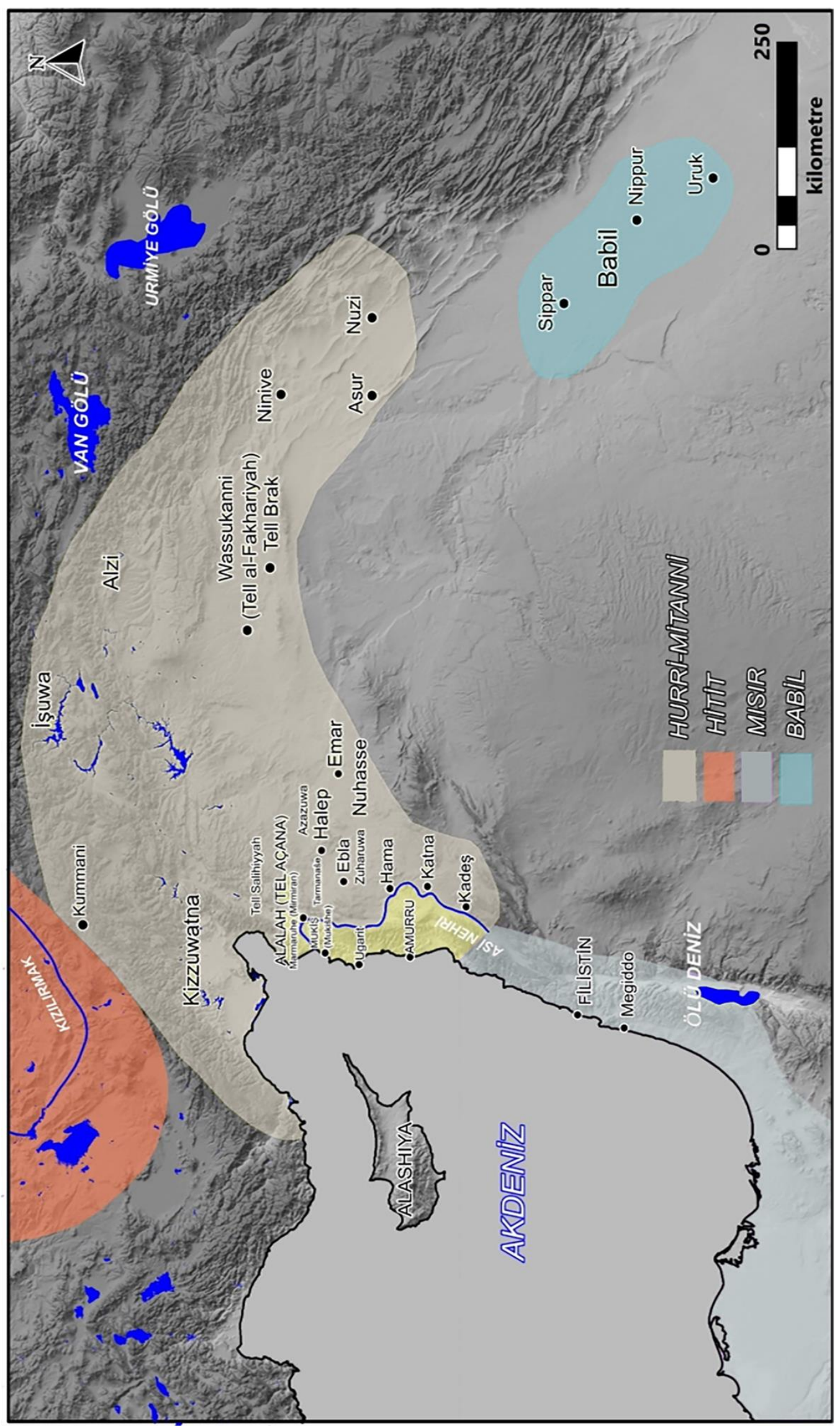

Ek 1 - Hurri-Mitanni Devlet'nin yaynlım haritası (Roaf'ın (1990,134) haritasından düzenlenmistir) 